\title{
El desarrollo de los métodos del trabajo de campo en la antropología social
}

\author{
Audrey I. Richards*
}

\section{Nota preliminar}

\author{
En las páginas siguientes se da una corta visión histórica de las técnicas usadas \\ por los antropólogos sociales para obtener sus datos en el campo. En el pasado \\ esas técnicas han sido diferentes, y en parte aún lo son, de las que usan los so- \\ ciólogos que estudian comunidades modernas y cuyos objetivos teóricos muchas \\ veces han sido distintos de aquellos de quienes estudian la sociedad primitiva.
}

\begin{abstract}
"The Development of Field Work Methods in Social Anthropology" fue publicado originalmente en inglés en 1939 en el libro The Study of Society. Methods and Problems, editado por sir Frederic Bartlett, Morris Ginsberg, Ethel John Lindgren y Robert Henry Thouless. Pedro Carrasco hizo la traducción al español en 1944 cuando aún era estudiante de la Escuela Nacional de Antropología y una copia mimeografiada se reprodujo y se difundió. En 1957, el Instituto Nacional Indigenista hizo una nueva reproducción en mimeo del artículo en español y una copia se conserva en la sección de separatas de la biblioteca Ángel Palerm del Ciesas. La separata, sin embargo, circulaba sin las llamadas y las referencias bibliográficas del original. En el 2012, el profesor Roberto Melville, investigador del Ciesas (Ciudad de México) y coordinador de Clásicos y Contemporáneos en Antropología, recuperó todas las referencias bibliográficas que se incluyen en la versión que presentamos. El ICANH agradece al profesor Roberto Melville y al Ciesas México por otorgar los permisos de reimpresión de este texto clásico de la literatura antropológica a la Revista Colombiana de Antropología (RCA). La revista ha realizado correcciones menores a la versión original para adaptar el texto a las normas actuales de puntuación y ortografía, y con el fin de adecuar el manuscrito a las normas formales de la RCA, que se rige por The Chicago Manual of Style, 16 th. [N. de la e.]
\end{abstract}

** Audrey Isabel Richards (1899-1984). Antropóloga y educadora inglesa conocida por sus investigaciones y trabajos aplicados entre varios pueblos de África del Este en alimentación, nutrición, agricultura y economía. Luego de pasar su adolescencia en la India, viajó a Inglaterra, donde estudió ciencias naturales y obtuvo un doctorado en la London School of Economics con la orientación funcionalista de Bronisław Malinowski. Bajo la administración colonial británica se desempeñó como profesora en la Universidad de Witwatersrand en Johannesburgo y en la Universidad de Makerere; en Uganda dirigió el East African Institute of Social Research. También se desempeñó como docente en la Universidad de Cambridge, donde fundó el Centro de Estudios Africanos en 1965. Sus investigaciones, basadas en el trabajo de campo intensivo, están compiladas en varios libros: Hunger and Work in a Savage Tribe (1932); Land, Labour and Diet in Northern Rhodesia (1939); Chisungu: A Girl's Initiation Ceremony among the Bemba of Northern Rhodesia (1956) y The Multicultural States of East Africa (1969). Con la reproducción de este texto clásico, la RCA rinde homenaje a una pionera de la disciplina. 
Un ejemplo es la frecuencia con que preocupa al antropólogo el problema de reconstruir la historia y la organización social de comunidades que no han dejado registros escritos. Por otra parte, ciertas condiciones especiales que el antropólogo encuentra en el campo motivan algunas de las diferencias en la técnica. Ciertas dificultades, como la lejanía del lugar estudiado, el tamaño de las comunidades y su analfabetismo, han limitado los tipos de observación posibles para el antropólogo, mientras que otras condiciones han sugerido nuevos problemas a investigar que han llevado al desarrollo de técnicas de observación que raramente se han ensayado en el estudio de sociedades modernas.

En el curso de este trabajo se encontrarán diferencias entre las diversas escuelas antropológicas en la manera de plantear los problemas teóricos, sin embargo, no es nuestro intento describir ni valorar las contribuciones de cada escuela. Solo mencionamos teorías antropológicas en cuanto que han inspirado nuevos tipos de trabajo de campo, por lo tanto, se omiten muchas contribuciones importantes. Igualmente se ha de entender que las monografías citadas no son precisamente las que dan información más completa sobre cierta cultura sino aquellas que ilustran más claramente diferentes tipos de observación.

\section{Introducción}

Como las primeras generalizaciones de la ciencia antropológica se basaban en material recogido por observadores no preparados, su alcance estuvo determinado por el accidente de la curiosidad del observador. Se considera que la tarea del antropólogo, diferente de la del mero observador, consistía en la clasificación de los datos y en la elaboración de deducciones sacadas de esos datos ${ }^{1}$. La primera edición de Notes and Queries on Anthropology fue publicada por la British Association for the Advancement of Science en 1874 para "fomentar observaciones antropológicas exactas de parte de los viajeros y para información que se

1 Tylor y Bastian hicieron muchos viajes, pero no realizaron un estudio sistemático de algún pueblo primitivo. Durkheim, Frazer, Graebner, Hobhouse, McLennan y P. Wilhelm Schmidt, para mencionar solamente unos pocos autores que hicieron importantes contribuciones teóricas a la antropología, no llevaron a cabo ellos mismos una investigación de campo. Westermarck estudió personalmente a los pueblos marroquíes, pero él es mucho más conocido por su investigación comparativa. 
necesita para el estudio científico de la antropología en el gabinete” (The Royal Anthropological Institute 1874, IV).

El material usado en las primeras monografías etnológicas fue recogido casi siempre por personas especializadas en otras ciencias o cuyos intereses se inclinaban a otros temas. El descubrimiento de Morgan del llamado sistema clasificatorio de parentesco, que discutieron y analizaron los antropólogos de los próximos setenta años, fue llevado a cabo en el curso de estudios lingüísticos entre los iroqueses en 1844, y Franz Boas recogió los datos para su primer trabajo etnográfico durante una expedición geográfica a la tierra de Baffin en $1887^{2}$. Alfred Cort Haddon se interesó en los pueblos primitivos cuando investigaba la fauna marina de las islas del estrecho de Torres en 1888, y el trabajo de Spencer y Gillen sobre las ceremonias totémicas de los australianos, en el cual se habrían de basar Frazer, Durkheim y, más tarde, Freud para gran parte de su trabajo teórico, fue también el resultado de una expedición zoológica dirigida en este caso a la Australia Central.

El gran interés que despertaron tales publicaciones motivó que se escribiera una serie de monografías de pueblos primitivos por europeos que habían vivido entre ellos y que poseían un conocimiento considerable de sus costumbres e idiomas, aunque les faltara preparación especial. Muchas de estas monografías son de alta calidad y constituyen todavía nuestra principal fuente de información en el caso de varias tribus.

Al mismo tiempo, hubo especialistas en antropología que emprendieron expediciones con el propósito declarado de estudiar una o más comunidades primitivas, empezándose entonces a discutir la técnica de observar y registrar los hechos etnológicos. La distinción hecha al principio entre el señor que recogía información en el campo y los que la examinaban e interpretaban en casa ya ha desaparecido y se da por sentado que el antropólogo debe tener experiencia de trabajo de campo, de la misma manera que el biólogo debe trabajar en el laboratorio. En la mayoría de los cursos de antropología actualmente se considera que es necesario dar alguna preparación para el trabajo de campo, por rudimentaria que sea.

2 A partir de este interés, en 1899 organizó la primera expedición antropológica británica al estrecho de Torres, invitando para este propósito a William McDougall, Charles Samuel Myers, Sidney Herbert Ray, William Halse Rivers, Charles Gabriel Seligman y Anthony Wilkin (Report of the Cambridge Anthropological Expedition to Torres Strait 1901-1935). 


\section{Tipos de investigación}

Como es natural, los tipos de observación hechos hasta ahora en sociedades primitivas han estado determinados por las teorías de los investigadores. Es imposible escribir una "relación puramente descriptiva" de cualquier cultura por sencilla que esta sea. Los hechos anotados son el resultado de una selección consciente o inconsciente, hecha de acuerdo con los intereses o teorías del autor, aun en el caso de que este se abstenga de presentar una interpretación especial de esos mismos hechos. La gran cantidad de material que pretende abarcar el antropólogo al describir toda la vida de una tribu hace esta selección todavía más arbitraria.

En las relaciones más antiguas se anotaron, en primer lugar, aquellas costumbres que más llamaron la atención a los europeos por ser distintas a las suyas, y es preciso admitir que todavía es un estímulo importante para la investigación antropológica el valor que como "cosa curiosa” tienen las instituciones indígenas. Pero las metas teóricas de los investigadores se pueden dividir aproximadamente en dos tipos.

1. La recolección de datos sobre varias sociedades diferentes para estudiar sus relaciones a) con pueblos del mismo nivel cultural de todas partes del mundo, o b) con pueblos que sabemos o creemos han existido en el pasado, o c) con tribus vecinas que viven o creemos han vivido en la misma región. Estos estudios los llamaremos etnográficos o históricos.

2. Estudios intensivos de ciertas culturas en funcionamiento tomadas por sí solas, considerándolas base para llegar a generalizaciones sobre la naturaleza de la sociedad humana en su totalidad ${ }^{3}$ o sobre los efectos de una variedad de formas culturales en la conducta del individuo. Llamaré a estos estudios investigaciones sociológicas intensivas.

Los dos puntos de vista que acabamos de distinguir han afectado irremediablemente al tipo de trabajo hecho en el campo. Los intereses del primer grupo, que eran los dominantes al principio, exigen la observación de cierto número de aspectos comparables, casi siempre formales, de tantas sociedades como sea posible. Por otra parte, los del segundo grupo nos llevan a un estudio detallado de las relaciones entre distintas instituciones humanas dentro del armazón de una sola cultura, de las directivas fundamentales que determinan las actividades

3 Cfr. la distinción elaborada por Alfred Reginald Radcliffe-Brown (1931) entre la antropología social como una ciencia generalizadora, como una rama de la sociología comparada, esto es, el estudio de cómo funcionan las sociedades, y la etnología, una disciplina histórica, esto es, el estudio del origen de las sociedades. 
humanas dentro de esa cultura y de la conducta individual en tanto que se ve modelada por normas tradicionales.

\section{A. Monografías etnográficas}

En Inglaterra, debido en gran parte a la influencia de la teoría de la evolución de fines del siglo XIX y principios del XX, los antropólogos aspiraban a clasificar las sociedades primitivas de manera semejante a como habían sido clasificadas las especies animales y trazar sus afinidades y sus orígenes ${ }^{4}$. Con este propósito hicieron mapas con la distribución de los pueblos del mundo y dieron descripciones de su físico, cultura material, estructura social y, en algunos casos, de sus idiomas. La cantidad de datos sobre cada uno de estos aspectos que se consideraba necesaria no era tan grande como para que un hombre no pudiera obtenerla. La última edición de Notes and Queries on Anthropology (The Royal Anthropological Institute 1929) da instrucciones para recoger datos entre estas cuatro categorías principales, que son las mismas que todavía se incluyen en los planes de estudio de las universidades inglesas.

Las primeras monografías etnográficas intentan conformarse a un plan semejante. Consisten en noticias generales sobre el territorio, el aspecto físico de la gente y los rasgos principales de la organización social agrupados en capítulos tales como sistema político y legal, parentesco, religión, magia, vida económica y cultura material. Se distinguen de las monografías posteriores más que nada en la cantidad de detalles anotados, menor uso de la psicología y análisis menos completos de las relaciones entre los distintos aspectos de la sociedad estudiada.

Y es que el propósito de estos primeros investigadores era reunir material para comparaciones etnográficas generales y para la clasificación de grupos primitivos, y no emprender estudios sociológicos intensivos. Muchos de ellos estaban también influenciados por los supuestos evolucionistas de que las sociedades primitivas existentes representaban supervivencias de etapas por las que una vez pasaron todos los pueblos, y de que, por lo tanto, entre los pueblos de cierto nivel cultural se encontrarían costumbres semejantes ${ }^{5}$. Por eso anotaron

4 Resulta interesante llamar la atención acerca de cuántos antropólogos pioneros tenían una preparación en biología (Haddon, Rivers, Seligman, Huxley, Baldwin, Spencer, y otros); obsérvese también el uso por parte de Haddon (1895) de conceptos biológicos para describir las formas de arte.

5 Por ejemplo, las investigaciones particulares acerca de las actividades rituales hacia los animales y las plantas, el mantenimiento de tabús alimentarios, que se descubrieron a finales del siglo XIX con el totemismo en una forma dramática en Australia y Norteamérica, y el intento de descubrir un concepto mágico religioso similar a la creencia en el maná descrito 
fragmentos de folclore, supersticiones, magia, etc., sin intentar explicarlos por el contexto cultural en que se encontraban, en gran parte debido a la influencia del estudio del folclore europeo que a fines del siglo XIX ${ }^{6}$ se estudiaba con fines semejantes. Otros aspectos de la cultura fueron observados por considerárseles notables o inexplicables por sí mismos y se les agrupó en capítulos de "ideas varias" o "creencias curiosas"7.

\section{B. Reconocimientos regionales}

Otro método por el que se han estudiado las relaciones entre distintas sociedades ha sido el de hacer un reconocimiento o inspección de los rasgos principales de la organización social de varias tribus vecinas. En las primeras expediciones organizadas con este objeto, los investigadores trataron de estudiar las tribus de una región no solo desde el punto de vista antropológico, sino también en sus aspectos geográfico, arqueológico o lingüístico. Un ejemplo es la expedición Jesup al Pacífico septentrional (Boas 1900) ${ }^{8}$. Además, hay varios reconocimientos de este tipo limitados principalmente a los aspectos social y físico, que fueron hechos por investigadores aislados. Por ejemplo, los trabajos de Seligman en Nueva Guinea (en 1905) y más tarde en el Sudán nilótico (Seligman y Seligman 1932) que visitó tres veces, entre 1909 y 1910, 1911 y 1912, y 1921 y 1922, habiéndole seguido Edward Evan Evans-Pritchard en 1926 (Evans-Pritchard 1937) ${ }^{9}$.

El continente australiano, debido a la uniformidad cultural y lingüística de sus naturales, se prestó particularmente para esta clase de trabajos. Entre los primeros investigadores de este tipo tenemos a Edward Micklethwaite Curr, Herbert Basedow, Robert Hamilton Mathews y Alfred William Howitt. Rivers llama

por Coordington en Melanesia (cf. John Henry Hutton que equipara al maná con el aren de los ao nagas en una nota a pie de página en Mill 1926, 257); y la concepción de la hasina en Madagascar de Arnold van Gennep (1904).

Véase The Study of Society. Methods and Problems, capítulo 14, sección I.

7 El cuestionario a sus investigadores de campo, que fue publicado por primera vez en 1907, contiene una sección encabezada como "Miscelánea de supersticiones", que conduce al observador a hacer indagaciones acerca de cosas raras como el trasvestismo, el mal de ojo, la couvade y cosas por el estilo (Frazer 1916).

8 Esta estaba integrada por un etnólogo, un arqueólogo y un lingüista, y su objeto era definido como "la investigación de las tribus, presentes y pasadas, de las costas del Océano del Pacífico Norte, la investigación de la historia del hombre en una área bien definida" (Boas 1900, II, 3-6).

9 Las contribuciones de Evans-Pritchards pertenecen, sin embargo, al grupo que aquí llamamos estudios sociológicos intensivos (sección D, más adelante). 
reconocimiento a su estudio de los pueblos de la Melanesia aun cuando nunca intentó escribir un relato puramente descriptivo de una región. Además, algunos empleados oficiales han hecho investigaciones etnográficas de varios distritos para usos administrativos y a menudo en relación con censos.

Los datos recogidos de esta manera son necesariamente más superficiales que los obtenidos por estudios especiales de una cultura, puesto que solo se puede pasar con cada tribu temporadas muy cortas y porque la investigación se realiza casi siempre mediante intérprete, pero cuando tratamos con una región desconocida es menester hacer primero un reconocimiento que sirva de base para trabajos posteriores ${ }^{10}$.

\section{El trabajo de campo como base para reconstrucciones históricas}

Probablemente, la mayoría de los estudios etnográficos de campo se emprendieron por lo que podemos llamar su interés histórico. Algunos antropólogos sostienen que la reconstrucción de la historia y de las afinidades de diferentes grupos étnicos es la tarea esencial del antropólogo y no el análisis sociológico o psicológico de diferentes formas culturales. Muchos etnógrafos han declarado terminantemente que su propósito era recoger datos que pudieran arrojar luz sobre el pasado ${ }^{11}$.

Las monografías escritas con una base histórica varían mucho en tipo y objetivo. Incluyen las contribuciones de a) los que mantienen la teoría evolucionista en su forma antes descrita y cuyo trabajo se ve influenciado por el deseo de buscar supervivencias de etapas anteriores; b) los que reúnen material para probar cierta idea sobre una migración o cualquier otra hipótesis histórica, y c) los que han intentado una reconstrucción más sistemática de la historia de grupos para los que no tenemos restos arqueológicos, usando métodos indirectos, tales como la recolección de tradiciones y el análisis de la distribución de diferentes

10 Para los detallados estudios comparativos de las áreas culturales por parte de los antropólogos norteamericanos, véase la sección $\mathrm{C}, 3$.

11 Es típica la afirmación de Roscoe (1911) de que la finalidad era "describir la vida social y religiosa de los baganda en los viejos tiempos" antes del arribo del hombre blanco (IX) y estudiar "aquellas razas primitivas de hombres que estaban disolviéndose frente a nosotros y que aún nos pueden revelar secretos que jamás podremos extraer de todas las tabletas de Babilonia o de las pirámides de Egipto" (VI). Véase también la descripción de Rivers (1911) de las modalidades del parentesco existentes como "indicadores ocultos de antiguas instituciones sociales" cuyo "estudio es esencial para el avance del conocimiento de la sociología prehistórica" (II, 3). 
rasgos culturales y lingüísticos bajo el supuesto de que formas comunes indican origen común o contactos culturales.

Es imposible resumir aquí estas contribuciones a la historia de las culturas primitivas, pero siempre que se ha adoptado un punto de vista histórico ha influido en el método de campo. Ha sido responsable por la búsqueda de sociedades "no tocadas” por la civilización y por el sentimiento de que era necesario estudiar sus costumbres lo más pronto posible, antes de que se perdieran sin remedio datos de tanto valor histórico ${ }^{12}$.

El intento de reconstruir la historia de diferentes grupos étnicos levanta indefectiblemente interés en las relaciones de una tribu con sus vecinos y en la recolección de hechos de varias sociedades distintas para comprenderlas mejor, mientras que el sociólogo se interesa en hacer una investigación detallada de la estructura social y los patrones psicológicos de solo una cultura. Ha hecho también que la atención de los antropólogos se dirija hacia los aspectos comparables $\mathrm{y}$, por lo tanto, formales de una cultura, y no a las fuerzas dinámicas fundamentales. El pasado ha sido reconstruido de muchas maneras, tales como el estudio de los datos arqueológicos, de las distribuciones de elementos culturales y de los recuerdos personales de los viejos (Sapir 1916). Los trabajos emprendidos con propósito histórico se pueden discutir en tres grupos:

\section{Investigación de hipótesis históricas especiales}

Son ejemplos de este tipo de trabajo los hechos entre algunas tribus africanas para buscar elementos de la cultura camita o de otras culturas antiguas, tales como los de Roscoe (1913) durante la expedición Mackie a Ucrania en 1919-1920, sugeridos por Frazer, y el estudio de Neek (1931) sobre varios pueblos de Nigeria hechos bajo la influencia de las hipótesis difusionistas de Elliot Smith y William J. Perry. También podemos mencionar varias expediciones de Frobenius a distintas partes de África en busca de elementos provenientes de culturas asiáticas invasoras (Frobenius y Wilm 1921-1922). La reconstrucción que hizo Rivers de la historia de la sociedad melanésica considerándola como una serie de migraciones de pueblos con distintas culturas inspiró también el trabajo de campo (Deacon 1934; Hocart 1929; Ivens 1917). Fison y Howitt (1880) estudiaron la

12 Véanse los comentarios de Bartlett (1937) sobre los efectos de esta percepción de urgencia en el trabajo de los antropólogos, comparado con el de los psicólogos sociales; también en Notes and Queries: "Entre más remota y desconocida sea una raza o tribu, más valiosa será la evidencia empírica derivada o resultante del estudio de sus instituciones" (1874, IV). Hay que recordar que las primeras investigaciones antropológicas se realizaron principalmente en Oceanía y Norteamérica, donde las razas primitivas estaban desapareciendo a un ritmo alarmante. 
nomenclatura del parentesco entre las tribus australianas a petición de Morgan, quien quería obtener material para ilustrar su idea de que hay varias etapas en el desarrollo de las estructuras del parentesco.

\section{Círculos culturales (kulturkreise)}

Los discípulos de Ratzel, tales como Frobenius, Graebner, Ankermann y más tarde Schmidt y Koppers, han intentado introducir un método más sistemático en el estudio de la historia primitiva. Su trabajo se originó de la clasificación sistemática de colecciones de museo, que dio por resultado estudios a gran escala de la distribución de ciertos rasgos culturales, la elaboración de complicados mapas de distribución y, finalmente, la enunciación de ciertas leyes de difusión cultural relacionadas al concepto de círculo cultural (kulturkreise). Un círculo cultural es un complejo de rasgos asociados que incluyen instituciones sociales, formas del ritual y artefactos, cada uno de los cuales se ha mezclado con otros círculos culturales en el curso de la historia. Al poner en mapas esos círculos han resultado ciertas hipótesis sobre el poblamiento de Oceanía, África, Sudamérica y otras regiones, algunas de las cuales han sido puestas a prueba en el campo. Frobenius hizo varios viajes a diferentes partes de África en busca de datos arqueológicos y, notando la ausencia o presencia de ciertos rasgos de organización política, arte, cultura material, etc. (Frobenius y Wilm 1921-1922). Koppers (1924) visitó Sudamérica y Schebesta $(1927,1933)$ a varias tribus de pigmeos, pero ni el Instituto Frobenius de Frankfurt ni la escuela etnológica de Viena han organizado el trabajo de campo en tan gran escala como los estudiosos norteamericanos.

\section{Reconstrucciones históricas y trabajo de campo en la escuela norteamericana}

La antropología norteamericana contemporánea muestra dos tendencias principales. La primera es fundamentalmente histórica, puesto que trata de reconstruir la historia y las conexiones mutuas de las tribus de Norteamérica mediante un análisis de tipo muy complejo y preciso de la distribución de rasgos culturales $^{13}$. La segunda es de índole esencialmente psicológica, puesto que trata de comparar lo que podríamos llamar la suma total de las actitudes, intereses y normas sociales características de una tribu con los de otras, y describir al individuo

13 Comparar el relativamente pequeño número de rasgos culturales o "síntomas" que enlistan Graebner o Frobenius con los detallados análisis de minúsculas variaciones en las formas culturales que se mencionan al final de esta sección. 
como producto de tales influencias culturales. Estas dos tendencias tienen su origen en el trabajo de Boas ${ }^{14}$, pero actualmente sus técnicas son muy distintas. Discutiremos ahora las del primer grupo dejando las del segundo para más adelante (sección D, 2).

Los antropólogos americanos protestaron contra el evolucionismo de los primeros teóricos ingleses y su intento de generalizar sobre la naturaleza del hombre primitivo usando datos de todas partes del mundo. El mismo Boas declara desde el principio que su interés era determinar el grado de variación de diferentes formas culturales entre tribus vecinas, más que encontrar los elementos comunes a todas ellas. Cualesquiera que sean los factores que motivan esa diversidad - geográficos o históricos-, insistió en que debería estudiarse con precisión científica y dentro de los límites de una región determinada sin meterse a reconstruir la historia de los cinco continentes. El resultado fue una serie de estudios de varios grupos étnicos más precisos y completos que los que hay para cualquier otra parte del mundo. Como ejemplos tenemos el trabajo del propio Boas sobre los idiomas, mitos, organización social y cultura material de las tribus de la costa del noroeste americano, el estudio de Kroeber sobre los indios de California y el de Lowie sobre los indios de las llanuras.

Pero poco a poco se desarrolló la orientación de intereses. Clark Wissler sentó la base para la clasificación de los pueblos de América demarcando áreas culturales, grupos de tribus asociadas por un medio ambiente especial, una misma manera de conseguirse la alimentación y un número de rasgos comunes lo bastante grande para justificar la suposición de que tienen un origen común (Wissler 1922, 1923).

Un número creciente de monografías permitió hacer mapas más detallados de las áreas culturales y la determinación de las relaciones de diferentes tribus, según su distancia del centro cultural en que se encuentra el mayor número de rasgos característicos o de las áreas marginales en que empiezan a aparecer rasgos de las otras áreas culturales vecinas. De esta manera, el resultado de los estudios de distribución geográfica se ha traducido a una secuencia cronológica mediante el empleo de suposiciones teóricas, como por ejemplo que los rasgos más extendidos son los más viejos, etc.

No solo se han intentado reconstruir las conexiones genéticas entre diferentes grupos étnicos, sino que también se han lanzado generalizaciones sobre la naturaleza del contacto cultural, de la difusión del préstamo y de la adaptación, “fenómenos dinámicos del cambio cultural” (Herskovits 1938a). De esta 
manera se han hecho estudios comparativos sobre folclore, tecnología, lingüística, clanes y ceremonial. La colección de ensayos de Spier (1921) sobre la danza del sol de los indios de las llanuras y el examen de Lesser (1933) sobre los cambios en el juego de manos de la danza del fantasma entre los pawnee son ejemplos de este tipo de trabajo.

En los últimos años, Kroeber y sus discípulos han tratado de expresar tales datos de distribución en términos cuantitativos. Han dividido los rasgos originales en cierto número de caracteres que tratan como unidades, cuya presencia o ausencia entre tribus vecinas piensan que indica conexiones históricas ${ }^{15}$. Los distintos elementos culturales así aislados han de ser por fuerza de carácter formal, y varían desde detalles complicados de la decoración de la cerámica y la cestería hasta instituciones como el potlach, conceptos religiosos como la actitud ante el creador, detalles de la nomenclatura de parentesco, estructura del clan, temas del folclore y costumbres como la postura de la mujer durante el parto. Kroeber distinguió 800 elementos separados al estudiar las afinidades de las tribus del norte de California, los cuales fueron reducidos a 400 por Klimek (1935), quien sacó los coeficientes de semejanza entre 500 pueblos con relación a la presencia o ausencia de todos esos rasgos. Esta manera de determinar las conexiones entre tribus mediante una enumeración de los elementos culturales comunes, y la técnica de campo que trae consigo, es el método de la antropología norteamericana que más se aparta de los “estudios sociológicos intensivos” descritos en la sección D.

El desarrollo de las técnicas de campo en Norteamérica se ha visto influenciado por intereses teóricos, por la naturaleza de los pueblos estudiados y por las oportunidades para trabajar. La presencia de un gran número de tribus indígenas con variaciones culturales muy marcadas que viven en estrecho contacto entre sí y con los blancos, pero en ambientes naturales muy distintos, ha traído todo el interés hacia el problema de la diferenciación. El hecho de que sean tan pocas las culturas indígenas que siguen funcionando en las condiciones anteriores a la influencia blanca ha dado por resultado que gran parte del trabajo de campo en Norteamérica ha consistido en recopilar textos de hombres y mujeres que recordaban su vida antigua descuidando la observación de la moderna vida

15 A partir de los 158 rasgos utilizados en una comparación de las tribus del noroeste californiano con los pueblos vecinos, Kroeber y Driver (1932) distinguen 15 diferentes tipos de casas, identificando como rasgo cultural aislado la presencia o ausencia, por ejemplo, de separaciones entre 12 y 20 pies de ancho, comparados con las de 30 a 40 pies de ancho, o más de 60 pies de ancho, mencionando el uso de redwood, sugar-pine, cedar bark y otros. Gifford (1922), al estudiar la suma de interrelaciones conceptuales de 50 sistemas de parentesco, se topa con 37 usos clasificatorios diferentes de los términos de parentesco. 
indígen ${ }^{16}$. La existencia de documentos históricos de la época de la primera llegada de los europeos ha facilitado el estudio cronológico de muchos de estos grupos, y el temprano desarrollo del interés de los americanos en la antropología, las proximidades del campo de trabajo y las facilidades para la investigación han hecho posible la organización de investigaciones comparativas detalladas de un tipo que no se ha ensayado en otras partes.

\section{Estudios sociológicos intensivos}

En el tipo de trabajo de campo que he llamado investigación sociológica intensiva, el antropólogo no está interesado en trazar las relaciones entre culturas en el espacio o en el tiempo, sino en descubrir las relaciones íntimas entre las diferentes instituciones de una cultura dada. Trata de descubrir la naturaleza de la cultura humana por medio de un estudio muy detallado de una sociedad particular, de la organización de las actividades e intereses de sus miembros y de las fuerzas que los mantienen unidos en el grupo, y no le importan "cuáles son los 'detalles' que sirvan para clasificar una tribu aparte de sus vecinos" (Lowie 1935, XVII). Los antropólogos partidarios de esta tendencia han atacado el punto de vista predominante histórico de algunos de sus colegas. Han criticado sus métodos para reconstruir secuencias cronológicas mediante el análisis cuantitativo de la distribución de rasgos culturales, e insisten en la naturaleza integral de la cultura humana y en el peligro de elementos aislados sin comprender el papel que desempeñan en la totalidad de la cultura ${ }^{17}$. Han llegado incluso a poner en duda el valor de las reconstrucciones históricas y se han interesado casi exclusivamente en determinar las funciones de instituciones determinadas en sociedades vivas sin especular sobre su significado en la historia ni en la evolución. De aquí el uso del término antropología funcional que primero empleó Malinowski y después pasó a designar todo un tipo de análisis cultural (véase la sección D, 1)

16 Klimek defiende el uso de un cuestionario acerca de 1.000 rasgos culturales entre los indios de California con este razonamiento: ayuda a poner atención a las viejas culturas como diferentes de aquellas híbridas en las cuales ellos viven ahora (Klimek 1935, 10), y es interesante que estas culturas híbridas solo recientemente han comenzado a estudiarse. Spier, en su relato de la tribu yaman, se lamenta de no haber sido capaz de completar una descripción de la vida tribal con un hombre viejo ("Yaman Tribes of the Gila River" 1933). Cfr. también a Lowie (1935, XXI).

17 Cfr. Radcliffe-Brown (1931): "El significado de un elemento solo puede establecerse cuando la cultura es considerada como un conjunto de partes entrelazadas" (155), y Malinowski: "la cultura no debe tratarse como una aglomeración suelta de costumbres, como un saco de curiosidades antropológicas, sino como un conjunto viviente e interconectado" ("Social Anthropology", Encyclopaedia Britannica 1929, XX: 864). 
y, también, la insistencia de parte de Radcliffe-Brown de que la antropología es en realidad sociología comparada.

Si bien es verdad que los primeros etnógrafos también observaron y describieron "sociedades enteras" - Boas y otros norteamericanos insistieron a menudo en la conexión entre diferentes aspectos de la cultura-, la visión teórica de los funcionalistas los ha llevado a hacer análisis mucho más detallados de las interrelaciones de diferentes instituciones en una comunidad que los hechos anteriormente. Tales investigadores han pasado largas temporadas estudiando en el campo una sola comunidad, usando el idioma de los naturales y participando en la vida de la tribu, de manera que han podido escribir una serie de monografías que dan una visión más completa de la vida indígena que cualquier trabajo anterior ${ }^{18}$; además, han añadido una documentación detallada sobre la conducta de los individuos y grupos a las descripciones de los elementos formales de la estructura social y de la cultura material, únicos temas que antes se estudiaban ${ }^{19}$.

\section{Análisis funcional}

Malinowski, en su obra sobre las islas Trobriand (1915-1920), fue el primero en demostrar las posibilidades de una investigación sistemática en el campo y su insistencia constante en problemas metodológicos ha influenciado profundamente el desarrollo de la técnica de campo. Con este objeto, ha clasificado las instituciones fundamentales de la sociedad, a las que él considera corporaciones organizadas de actividades realizadas por todos los grupos humanos para satisfacer una necesidad biológica primaria, que se relacionan en parte al ambiente de maneras definidas culturalmente y que se asocian con ciertos objetos materiales, tradiciones o mitos teniendo cada institución aspectos políticos, económicos, legales, educativos, religiosos y otros ${ }^{20}$.

Cfr. el prefacio de Frazer al trabajo de Malinowski (1935): "Él ve al hombre, para decirlo así, en un círculo, y no en un plano" (IX). Herskovits $(1937,22)$ también utiliza la palabra presentación redonda para describir este tipo de trabajo.

19 La relación entre la teoría antropológica y las oportunidades de campo queda mejor documentada por este hecho. El investigador de campo, norteamericano o británico, que ha estudiado por periodos prolongados una cultura viva tiende a adoptar esta perspectiva sociológica. Aquellos que han tenido que reunir información a partir de sobrevivientes de culturas extintas, inevitablemente demuestran más claramente un interés histórico. está vinculada a una localidad particular y a un sistema de viviendas. Sus miembros sostienen un cuerpo organizado de creencias respecto a la descendencia, y aceptan una serie de obligaciones legales como entre el esposo y la esposa, los padres y los hijos, y otras similares; toda la familia y el grupo de parientes tiene aspectos específicos de orden político, económico, religioso, educativo y otros (Malinowski 1931). 
La definición malinowskiana de una “institución” no ha sido aceptada por todos los sociólogos pero ha estimulado a recoger en el campo informaciones lo más completas posible, obligando al investigador a considerar cualquier costumbre desde todos los puntos de vista imaginables. El enorme campo de observación que tal esquema analítico requiere se ve en la reciente obra de Malinowski (1935) sobre la agricultura de las Trobriand, la cual incluye no solo una descripción como la que necesitaríamos para un estudio comparado de plantas cultivadas, instrumentos, naturaleza general de la actividad y ceremonias asociadas a ella, sino también un relato del medio ambiente, de las reglas que atañen a su empleo, de los títulos míticos de propiedad, de las actividades primarias del cultivo y de las secundarias a ellas asociadas, del sistema de agrupaciones sociales que acompañan a la habitación y propiedad de la tierra y a la producción y distribución de las cosechas, de los caudillos a quienes obedece la tribu, del sistema de reglas legales y de otra índole que los liga, y de la ciencia y creencia tradicionales por las que se guían.

Sea o no posible presentar mediante esta técnica el funcionamiento completo de toda una cultura por pequeña que sea, es evidente que un investigador que use un esquema tan completo para el análisis cultural "hará observaciones cabales y sistemáticas en el campo”. De hecho, Malinowski, sus discípulos y algunos otros antropólogos que han hecho estudios sociológicos detallados de este tipo, cualquiera que fueran sus teorías, han presentado su material en forma de discusiones de un aspecto de la sociedad con todas sus ramificaciones y no han intentado describir una cultura en su totalidad ${ }^{21}$.

Casi no se ha intentado todavía hacer estudios comparados con base en tales estudios funcionales detallados, principalmente, debido a la falta de datos suficientes de ese tipo. Radcliffe-Brown (1931) ha insistido a menudo en este punto, abogando por que se haga una investigación comparada de una región mediante estudios funcionales de cada una de las culturas que en ella habitan.

En Australia, donde las culturas son relativamente homogéneas, con ciertas referencias lingüísticas, organizó una investigación sistemática de la morfología y funciones del parentesco y el totemismo, con el objeto de clasificar los datos obtenidos ${ }^{22}$. Propósito semejante tiene su estudio de las funciones del tío

21 Véase cómo trata Malinoswki el comercio (1922), el sexo (1929), la magia y la agricultura (1935); Firth (1936) el parentesco primitivo; Evans-Pritchard (1937) la magia; Fortune (1932) la brujería; Mead (1919) la adolescencia; Bateson (1936) los rituales mortuorios y los patrones de conducta entre los dos sexos; Hogbin (1934b) la ley; Richards (1935) la dieta y la economía. 
materno en varias sociedades surafricanas. El reconocimiento más detallado de Elkin en Australia occidental y meridional y en Nueva Gales del Sur (1927-37) y el trabajo de los investigadores enviados por el Australian National Research Council intentan producir resultados comparativos (Elkin 1932, II, 296-333; 1933).

\section{Estudios de patrones culturales}

Uno de los conceptos clave de la antropología norteamericana contemporánea es el de la organización de los sentimientos, intereses y valores de un grupo dado formando un patrón característico. Se han usado palabras tales como $p a-$ trón, orientación, estilo o tendencia para describir la influencia de los valores dominantes de una comunidad sobre sus miembros individuales, para explicar el porqué de adoptar o rechazar nuevos elementos culturales y para sentar las bases que nos permitan comparar el temperamento y las normas sociales de diferentes grupos étnicos.

Este concepto ha suscitado la cuestión de la relación entre temperamento, estructura social, ambiciones económicas y formas rituales y literarias, y sus defensores sugieren que ahí está la base para comparar las culturas en su totalidad, tarea que no han emprendido Malinowski ni sus discípulos. Aún está por verse si esta teoría influenciará la técnica de campo. Actualmente, el término patrón se usa indistintamente para designar a la institución dominante en una cultura, por ejemplo el potlach en la Costa del Noroeste, los cambios recíprocos entre los trobriandeses y la gran familia entre los tamalas; las normas tradicionales de conducta social o ritual, por ejemplo, si la pena se expresa quieta o violentamente; la expresión literaria de valores, tales como mitos y proverbios, y, finalmente, la ambición más fuerte de la gente, por ejemplo, el deseo de poseer ganado o de adquirir fama en la guerra ${ }^{23}$. Por lo tanto, este concepto es difícil de usar como base para comparaciones exactas. Para describir los principios más importantes que integran una sociedad hace falta un análisis detallado de las interrelaciones de sus diferentes instituciones, pero para clasificar culturas según categorías psicológicas y para caracterizar la conducta social de un grupo en lo que tiene de distinta de otro, es necesario un tipo especial de observaciones en el campo y una definición exacta de los términos usados. Todavía no se ha logrado alcanzar estos requisitos, pero este concepto de orientación cultural ha producido

23 Cf. Benedict $(1930,1935 b)$, que usa términos como apolíneo y dionisíaco para clasificar a las culturas primitivas. Linton (1936), describe la orientación de los intereses de un pueblo amante de la guerra y de otro donde la organización familiar está en la base de la agrupación social. Mead (1935) también usa la idea de patrones culturales. 
un nuevo e interesante estilo de presentar los datos etnográficos y la recopilación de material sobre el mecanismo educativo de los pueblos primitivos ${ }^{24}$.

\section{E. La investigación antropológica y los problemas administrativos}

Los lazos entre los estudios antropológicos y la administración colonial han sido siempre estrechos en Inglaterra. Algunas de las mejores monografías sobre pueblos primitivos fueron escritas por empleados del Gobierno y pronto fue reconocido que para evitar dificultades con los indígenas convenía conocer sus costumbres $^{25}$. El trabajo de los antropólogos ha sido útil para explicar al europeo costumbres indígenas extrañas y, en varios casos, los gobiernos han enviado gentes con preparación antropológica para investigar relaciones desconocidas o para decidir cuestiones de sucesión o de organización política en general ${ }^{26}$. En Nigeria, a partir de 1934, un grupo de administradores fue empleado para estudiar la organización política de las tribus de los territorios del norte. La adopción de la política de "gobierno indirecto", que hace uso de las instituciones indígenas, ha hecho necesarias en muchas colonias inglesas de África las investigaciones de este tipo.

Entre los etnógrafos de profesión, el desarrollo de la antropología como ciencia aplicada ha avanzado rápidamente, sobre todo en Inglaterra, África del Sur y Australia, de acuerdo con la tradición colonial británica ya descrita. Desde 1929, Malinowski insistió en que los estudios detallados sobre el régimen de propiedad, la organización política, la economía, el idioma, etc., que resultan de una investigación sociológica intensiva, podrían ser de valor inestimable para los administradores que tratan con los indígenas, y pedía que se emplearan etnógrafos para realizar investigaciones puramente objetivas de ese tipo (Malinowski 1929a, 1938). Es natural que los que han adoptado el punto de vista funcionalista u otro semejante, y que han anunciado su propósito de evitar "pasiones de

24 Mirar particularmente el trabajo de Mead, por ejemplo, Coming of Age in Samoa (1919).

25 Cf. Edwin William Smith (1927) para tener una expresión de este punto de vista. Tan temprano como en 1896 hubo un intento de crear un buró imperial de etnología para reunir datos considerados de "inmenso valor para la ciencia y para el mismo Gobierno", tal como lo relata Myers en The Science of Man in the Service of the State (1929). Véase también a Seligman (1932, XVII-XIX). Ernest William Chinnery en Nueva Guinea; Robert Rattay en la Costa de Oro; Charles Meek en Nigeria y John Henry Hutton en la India; véase también la argumentación del trabajo del servicio para el Congo Belga, descrito por Verhulpen en Baluba et Baluhaisés du Katango (1936). 
anticuarios” para estudiar los pueblos primitivos tal como son en el mundo en que realmente viven, se hayan interesado especialmente en los problemas de cambio y adaptación social.

Todavía no está claro si los antropólogos lograrán que se les considere consejeros técnicos de los gobiernos coloniales para los aspectos sociológicos de la administración. Evidentemente es difícil hacer investigaciones científicas a las órdenes de un gobierno, tratándose de cuestiones sociales sujetas a controversia. Algunos africanistas han sido consultados sobre problemas específicos por los administradores de las regiones por ellos estudiadas y han suministrado informes sobre problemas acerca de la propiedad de la tierra, cría de ganado, alimentación, matrimonio, código legal, herencia del cacicazgo, educación y maneras de obtener datos sobre la organización social de una región (Read 1938) ${ }^{27}$. En 1935, se hizo en Tanganica un experimento de colaboración entre un antropólogo y un administrador; el último señaló problemas definidos, como la naturaleza de la organización política, el sistema legal, el régimen de propiedad, los efectos del registro civil sobre los divorcios y las consecuencias de la pena de muerte, y el antropólogo recogió datos adicionales sobre estos temas en el curso de su trabajo.

Otro experimento es el establecimiento del Rhodes-Livingstone Institute en 1938, con tres antropólogos en su personal, uno de los cuales está investigando los efectos del desarrollo de las minas de cobre de Rodesia sobre la cultura indígena. Una expedición organizada por el Instituto Internacional de Lenguas y Culturas Africanas para investigar los problemas nutricionales de las tribus del Nasa se compone de un médico, un nutriólogo y un antropólogo, lo cual sugiere que la investigación etnográfica también será de valor para los servicios técnicos de los gobiernos coloniales en sus departamentos agrícolas, ganaderos, sanitarios y educativos. Sin embargo, este tipo de cooperación todavía está en pañales y el problema de salvaguardar la libertad y la objetividad científicas del etnógrafo, al tiempo que rinde sus servicios al gobierno de la región que estudia, está todavía por resolverse.

\section{F. Estudios de contacto cultural}

Casi toda la historia de la cultura es en esencia un estudio de acciones recíprocas entre distintas sociedades, sea a consecuencia de conquistas, yuxtaposiciones o interpenetraciones como las que se manifiestan en la difusión de objetos materiales, costumbres o ideas. Como hemos visto, las investigaciones históricas de

Cf. Hailey (1938, 45-49). 
la mayoría de los antropólogos norteamericanos han intentado reconstruir la secuencia de los pueblos de un área determinada y aclarar la naturaleza de los procesos de difusión, adaptación, asimilación o aculturación. La naturaleza del contacto entre diferentes tribus americanas o entre indios y europeos ha sido estudiada de tres maneras: por un examen cuantitativo de sus rasgos comunes, por el uso de documentos históricos que nos informan sobre un gran periodo de tiempo y por el análisis de las descripciones dadas por viejos de la comunidad sobre los cambios que ellos recordaban.

Más recientemente se ha intentado estudiar el proceso de aculturación por sí mismo y no como un producto secundario de las reconstrucciones históricas. En 1936, un subcomité del American Social Science Research Council trazó un esquema que ayudará a clasificar las diferentes formas de contacto cultural ya observadas y que indican nuevas direcciones de investigación ${ }^{28}$. Cierto número de etnógrafos como Herskovits, Mead, Clews Parsons, Radin y Redfield se han dedicado especialmente a estos problemas anunciando su intención de observar los cambios que actualmente están sucediendo en las sociedades indígenas y no aquellos que solo existen en la memoria de unos pocos ${ }^{29}$.

Los antropólogos ingleses han usado el término contacto cultural casi exclusivamente para designar los cambios producidos en los grupos indígenas por el impacto de la civilización europea. La despoblación del Pacífico que siguió a la ocupación europea ${ }^{30}$ estimuló el trabajo de campo sobre problemas de contacto cultural, como se ve en los escritos de Rivers (1911), Pitt-Rivers (1911) y Keesing (1928, 1934), y en 1903 se nombró una comisión para estudiar estos problemas en las Fiyi. El Institute of Pacific Relations fundado en 1920, que se reúne cada tres años, ha financiado investigaciones sobre las causas de despoblación. Los cultos religiosos que surgieron en Nueva Guinea como resultado del contacto europeo fueron descritos por Chinnery y Haddon (1917) y por Williams en 19231935 (1928, 1933). Más recientemente, el Instituto Internacional de Lenguas y Culturas Africanas ha auspiciado un plan quinquenal para estudiar los efectos

Herskovits (1938a) publicó este esquema conjuntamente con un resumen de los trabajos realizados por investigadores de campo, británicos y norteamericanos, acerca de este problema, y sugiere definiciones para términos como aculturación, asimilación, etc. Cf. también el intento previo de Bartlett (1923) para definir diferentes formas de contacto cultural, las sugerencias de Malinowski (1938) para hacer un análisis funcional del cambio cultural y el esquema que propuso Bateson (1935, XXXV).

Véase, por ejemplo, Herskovits (1938a, 1938b), Mead (1930), Redfield (1930) y Radin (1913, 137145). Ethel John Lindgren (1938) descubrió el contacto entre los reiner tungus y los cosacos rusos de Manchuria. poblaciones indígenas en Estados Unidos, Melanesia y Sudáfrica y África Occidental. 
producidos en once grupos diferentes por el contacto con los europeos. Es evidente que la insistencia de los funcionalistas en análisis muy detallados de las relaciones entre diferentes instituciones y los sistemas de ideas suministra una base excelente para estudiar los efectos dinámicos producidos por la alteración de un aspecto de la estructura social como resultado del contacto, y gran parte de este trabajo ha sido realizado por discípulos de Malinowski ${ }^{31}$.

Al estudiar cambios tan rápidos como los producidos por el impacto de una civilización industrial sobre un pueblo primitivo surgen en el campo ciertos problemas fundamentales que hay que tener en cuenta, cualquiera que sea el interés teórico del investigador. Uno de estos es la reconstrucción de los antecedentes históricos para formar un punto a partir del cual se puedan medir los cambios que han tenido lugar en la sociedad en cuestión. En este punto hay alguna diferencia entre el objetivo de los antropólogos americanos y el de los ingleses. Los primeros están interesados en reconstruir todas las etapas por las que ha pasado una cultura dada mediante el uso más completo posible de documentos y de los recuerdos de los viejos, y en determinar todas las fuentes de las que una cultura ha tomado sus diferentes elementos, averiguando si se han adaptado y si han desaparecido en el momento presente (Herskovits 1938a). De esta manera, presentan una secuencia histórica completa en cuanto lo permiten los datos disponibles. Los funcionalistas también usan datos históricos verídicos siempre que sea posible, pero usan los recuerdos de los viejos como un índice para saber qué cantidad de historia viva sobrevive e influencia a la conducta social contemporánea, preocupándose por observar detalladamente los cambios que están realizándose en el momento, más que en desentrañar el origen de todos los elementos que han contribuido a formar la cultura (Malinowski 1938).

Otro problema consiste en la adaptación de una técnica de campo desarrollada en el estudio de comunidades más o menos estáticas, a las condiciones de cambio rápido que trae consigo la adopción de la vida urbana, del trabajo asalariado, la adquisición de nuevas industrias, y el aprender a leer y escribir. Ha resultado necesario hacer primero un estudio de los rasgos generales de la cultura para estimar después el grado de variación producido por el contacto cultural. Mead (1919) intentó hacer esto en el caso de una tribu norteamericana seleccionando a un informante de cada una de tres generaciones y tratando de ver los cambios a través de sus relatos, los cuales completó con datos obtenidos del análisis de 160 hogares. Schapera $(1928,1935)$ ha hecho una serie de visitas a una

31 Myers Fortes, Sjoerd Hofstra, Monica Hunter, Lucy Philip Mair, Siegfried F. Nadel, Kalervo Oberg, Margaret Read, Audrey I. Richards, Isaac Schapera, Gunter Wagner, Godfrey Wilson. El trabajo de Ian Hogbin (1934a) en Polinesia es similar. 
comunidad sudafricana durante un periodo de ocho años, registrando todos los cambios que sucedían. Hunter ha comparado la cultura de los pondos de las aldeas con la de los que viven en granjas de europeos y con la de los que residen en zonas urbanas (Hunter 1934a, 335-350; 1934b, VII, 100-104; 1936); Richards (1932, 1935a) ha estudiado aldeas que habían tenido diferentes tipos de contacto con los europeos y usó censos sociológicos para estimar el grado de variación individual debida al impacto de la civilización occidental.

\section{G. Problemas especiales}

En los primeros tiempos, los etnógrafos, debido a lo lejano de su campo de trabajo, creyeron un deber recoger datos sobre todos los aspectos de la vida de una tribu aun cuando no estuvieron preparados especialmente paro ello. Más tarde, salieron expediciones para coleccionar artefactos, estudiar la música, el idioma o el folclore, para aplicar pruebas psicológicas o para psicoanalizar a miembros de grupos primitivos.

Entonces surgió una dificultad. El estudio de un aspecto especial de la cultura indígena, sin conocer el idioma y la estructura social de la tribu, ha dado deplorables resultados; lo mismo sucede si el etnógrafo hace estudios superficiales de un aspecto de la cultura sin estar preparado para ello. En realidad se han hecho muy pocos estudios especiales. El remedio sería organizar expediciones de antropólogos y especialistas ${ }^{32}$, o enviar a los especialistas a regiones donde ya se han hecho estudios sociológicos detallados ${ }^{33}$.

Una dificultad semejante surge en relación con el tipo de investigación intensiva que ahora realizan los antropólogos. La cantidad de detalles requeridos, y el intento de estudiar las variaciones individuales y los fenómenos de cambio cultural además de los rasgos generales, les obliga a dividir su trabajo en un esquema preliminar seguido de una investigación más detallada de ciertos problemas. Especialmente, cuando se emprende la investigación en regiones donde el contacto con los blancos ha sido grande, aparecen cuestiones para cuyo análisis es necesaria la ayuda de economistas, psicólogos, ecólogos, médicos, etc. Las posibilidades de cooperación según las líneas descritas aumentarán considerablemente junto con el número de estudios sociológicos disponibles de alta calidad.

Bartlett (1937) también sugiere esto. La expedición nutricional descrita anteriormente (sección E) es un ejemplo del tipo de trabajo que podría llevarse adelante.

33 Un ejemplo de esto está en el trabajo de Benedict (1935a) acerca de la mitología zuni en un área donde su cultura es bien conocida y donde ella tenía experiencia previa de trabajo de campo. Véase también el estudio de Schapera (1935) acerca de la ley tswana. 


\section{Métodos de observación}

El investigador de sociedades primitivas tiene ciertas ventajas en el campo. Las comunidades que estudia son tan pequeñas ${ }^{34}$ que las puede investigar como totalidades en funcionamiento y no como subdivisiones de una sociedad más grande. Puede recoger datos que muestren el funcionamiento de todas las instituciones fundamentales de una tribu dada y no se ve limitado, como es el caso en una civilización compleja, a estudiar solo un aspecto determinado. El tamaño del grupo también le permite entrar en contacto personal con mayor proporción de sus miembros de lo que sería posible en una comunidad moderna.

Además, las actividades económicas de una sociedad primitiva son por lo general tan sencillas que se necesitan pocos conocimientos técnicos para describirlas $^{35}$, y las ocupaciones individuales están tan poco especializadas que se puede suponer que, con unas pocas biografías detalladas y con observaciones sobre la vida social de uno o dos grupos locales, tenemos datos suficientes para sacar conclusiones sobre la totalidad de la cultura. También es importante recordar que los miembros de una comunidad primitiva siguen por lo común normas formales de conducta en sus relaciones mutuas, como las obligaciones, reglas de etiqueta, usos lingüísticos y de otra índole, que están definidos culturalmente entre los parientes. Este fenómeno hace posible formular generalizaciones sobre las normas de la conducta humana que serían muy difíciles de hacer en una sociedad más compleja. En casi todas las tribus primitivas el tipo de habitación facilita también la observación de las actividades domésticas en contraste con la mayoría de las sociedades europeas en las que cada individuo pasa encerrado por lo menos tres cuartas partes de su tiempo.

Otra ventaja del antropólogo es, aunque parezca paradójico, su completa falta de familiaridad con las costumbres del pueblo que estudia y que renueva constantemente sus intereses teóricos. Se arguye a menudo que las observaciones en el campo deben ser hechas por miembros educados del grupo a estudiar, puesto que tienen las ventajas de conocer el idioma y tener ya hechas numerosas amistades. Pero es dudoso si tales ventajas pesan más que la falta de curiosidad

Spencer y Gillen trabajaron entre unos 2.000 australianos (arunta), Malinowski entre unos 1.300 trobriandeses, Raymond Firth entre unos 1.200 tikopias, Reo Fortune entre 1.200 dobuanos y Mead entre unos 2.000 isleños de Manus. En cambio, los estudios de tribus africanas tienen comúnmente unas poblaciones más numerosas, entre 10.000 y 150.000 en África del Sur y África del Este, y hasta 500.000 en África Occidental.

Por eso un antropólogo puede hacer una buena descripción de una primitiva fundición de hierro, pero no podría pretender hacer una descripción adecuada de unos altos hornos sin la asesoría de un especialista. 
y el conflicto de valores que es casi siempre el principal estímulo para proseguir la investigación. Tenemos pocas descripciones sobre la manera de comer de los europeos tan detalladas como las que poseemos sobre los melanesios y africanos, y es notable que siempre que un hombre de ciencia ha observado su propia cultura nos ha dado mejores relatos de los aspectos políticos y ceremoniales de la vida que de los sucesos cotidianos más íntimos o de la cultura en su conjunto ${ }^{36}$. Por otra parte, el hecho de ser un extraño en la comunidad le da ciertas ventajas al antropólogo, pues le permite cruzar barreras infranqueables para un nativo ${ }^{37}$.

También hemos de tener en cuenta ciertas dificultades del trabajo de campo. Por ejemplo, el investigador tiene que trabajar casi siempre en idioma extraño y a menudo se encuentra con la desgana, e incluso hostilidad, de los que le tienen que dar informes. En la mayoría de los casos, ocupa un lugar para nada familiar en la comunidad que estudia, amenaza perturbar el curso normal de la vida y puede serle difícil participar en las relaciones sociales que se consideran normales en la tribu. Las regiones ocupadas por pueblos atrasados son a menudo tan poco accesibles que no puede acudir en busca de ayuda a especialistas de otras disciplinas, aunque se vea obligado a considerar sus problemas desde muchos puntos de vista diferentes.

Ordinariamente, los antropólogos tienen que usar estudios anteriores o estadísticas y documentos sobre la época en que trabajan. Las técnicas para vencer las dificultades de la falta de registros escritos ha alcanzado cierto grado de precisión gracias al trabajo de los antropólogos norteamericanos antes descrito; sin embargo, las reconstrucciones históricas logradas hasta la fecha nos dan un cuadro lleno de migraciones y contactos, pero sin dato alguno que se preste a comparaciones sociológicas ${ }^{38}$. Además, los gastos de la expedición obligan al

Rasmussen (1931), él mismo mitad esquimal y diestro hablante de la lengua, publicó un valioso compendio de relatos esquimales, magia, canciones y supersticiones, así como un vocabulario, pero él no nos proporciona una descripción íntima de la vida cotidiana. Herskovits (1938a) señala que la renuencia de un observador para registrar lo familiar es un inconveniente en el estudio del contacto entre un pueblo primitivo y una civilización europea, y cita (en la página 19) la afirmación de Schapera (1935) de que parece "una tontería registrar los detalles de una boda cristiana, o de la ceremonia de la confirmación, con la misma fidelidad, no digamos entusiasmo, con la que uno anotaría y registraría la reparación de un jardín o de una choza".

37 Cf. la discusión del "calor de lo extranjero" en los capítulos XIII y XVI.

38 La postura de Robert Staughton Lynd y Helen Merrell Lynd (1929) y de sus ayudantes que fueron capaces de comparar dos etapas del desarrollo de un típico pueblo del Medio Oeste en Estados Unidos, por medio de un análisis de periódicos y de registros municipales y de otro tipo, puede contrastarse con la del promedio de los antropólogos. En cambio, muchos antropólogos norteamericanos han disfrutado de los frutos de años de continua investigación hecha por sus predecesores, y también de la posibilidad de hacer repetidas visitas a sus áreas de trabajo de campo. Así, Lowie (1935, XIII-XVII), por ejemplo, menciona la primera visita 
antropólogo a realizar su investigación durante un número limitado de meses. Por lo tanto, lo que describe es solamente una visión parcial de la conducta de unos pocos individuos durante un poco tiempo, lo cual es evidentemente un método arbitrario de muestreo ${ }^{39}$. Claro que hay algunos europeos que han residido veinte o más años entre pueblos primitivos, pero no sé de ningún caso en que hayan hecho investigaciones sistemáticas durante todo ese periodo.

En general, los métodos antropológicos de observación reflejan los diversos intereses teóricos descritos en la sección II. Pero la línea de división entre los diferentes tipos de trabajo no es demasiado grande y las dificultades metodológicas de los modernos antropólogos se deben sin duda al hecho de que tratan de recoger informes desde todos los puntos de vista posibles a la vez.

Los métodos usados hasta ahora se pueden estudiar bajo los siguientes tópicos:

\section{A. Contactos}

El primer problema del antropólogo es entrar en contacto con la gente que va a estudiar, de manera que se preste a contestar sus preguntas y a permitirle observar, y en lo posible, a participar en sus actividades. Las sugerencias que se pueden leer en varios manuales antropológicos sobre la mejor manera de entrar en relacionas amistosas y evitar antipatías no son muy distintas de las que se pudieran hacer a cualquier persona que va a visitar un país extranjero, y todavía se parecen más a la conducta que debe seguir un sociólogo cuando llama a la puerta de un individuo de otra clase social que la suya. Las dificultades propias del antropólogo consisten principalmente en que necesita usar un idioma del que no hay gramáticas ni diccionarios y en diferencias culturales tan grandes que lo colocan por completo fuera de la sociedad que estudia. Además, puede suceder que los indígenas hayan adoptado cierta actitud hacia los paisanos del antropólogo que todavía restrinja más sus oportunidades.

La cuestión del idioma es muy importante y no hay duda alguna de que una vez resuelta quedan vencidas la mitad de las dificultades que hay para entrar con contacto. El observador puede empezar a recoger datos sobre el curso de

\footnotetext{
del príncipe Maximiliano a los indios crow en 1833, y él mismo pudo estudiarlos en 1907, 1910-1913 y 1931. Benedict (1935a) pudo comparar los resultados de su estudio de la mitología zuni con los de Cushing cincuenta años antes. El análisis de Lesser (1933) sobre el juego de pelota en la danza del espíritu está basado en el trabajo de Mooney en 1890. crónicos"; cf. Firth $(1936,128)$ y Bateson (Radcliffe-Brown 1931, 3).
} 
la vida diaria, ya no solo por medio de entrevistas formales, y poco a poco deja de ser un extraño en la comunidad. Pero para adquirir el mínimo de un idioma que se necesita para poder empezar a trabajar hacen falta por lo menos tres meses de trabajo intensivo y, a veces, si el idioma es difícil, todavía más.

Cuando se está haciendo un reconocimiento regional o cuando la temporada de trabajo es corta no se puede dedicar tanto tiempo a trabajos preliminares como es aprender un idioma, de manera que por lo menos la mitad de las monografías existentes han sido escritas mediante el uso de intérpretes, usando alguna lengua franca ${ }^{40} \mathrm{o}$ con un conocimiento insuficiente del idioma indígena.

Los propósitos de la investigación deciden cuál sea la solución a este problema. El trabajo con intérprete es satisfactorio para estudiar la distribución de ciertos rasgos, para recopilar textos y para hacer una inspección superficial. Muchos norteamericanos han escrito textos en alfabetos fonéticos y han empleado intérpretes experimentados. Lowie (1935) ha sugerido que, en vista de la dificultad extrema de algunos idiomas amerindios, es menos peligroso trabajar con intérprete que entender a medias lo dicho por los indígenas (XVIII-XX) ${ }^{41}$. Pero si el investigador está haciendo un estudio sociológico intensivo o trata de participar en la vida social indígena, es imprescindible conocer bien el idioma, por mucho tiempo que necesite para aprenderlo.

El grado en que un investigador puede vivir la vida indígena depende de su temperamento ${ }^{42}$ y de la gente con quien trata; sobre todo en lo referente a la actitud que tengan hacia los miembros de su raza ${ }^{43}$; el tipo de habitación también tiene algo que ver. Casi todos los etnógrafos están de acuerdo con que es imposible identificarse por completo con los indígenas. Herskovits (1937) dice que el etnógrafo, "especialmente si es un hombre blanco, tiene un alto grado de visibilidad social”. Pero cuando la vida de la tribu se desarrolla casi toda al aire libre,

40 En algunas sociedades sudafricanas el culto al europeísmo es tan fuerte que el nativo hace un tremendo esfuerzo por aprender inglés y hablarle al antropólogo en ese idioma.

41 Sin embargo, él recomienda el uso de la lengua nativa siempre que sea posible e insiste en la necesidad de tener un conocimiento suficiente para ser capaz de supervisar la traducción del intérprete (Lowie 1935). Véase también a Herskovits (1938b) que expresa un punto de vista semejante.

Cf. Malinowski $(1922,21)$. Bateson (1934) reclama que en todas las publicaciones "debe describirse el tipo al que pertenece el investigador". Esto podrá ser o no posible. Lindgren (1934, 1935) subraya la importancia de seleccionar un medio con el que haya una congenialidad o parecido temperamental, pero tenemos poca evidencia concluyente en torno a este punto. no tiene prestigio, ni apoyo oficial, y donde la seguridad de los viajeros depende en cierto modo de su relativa popularidad, es aconsejable hacer muy pocas preguntas y esperar las confidencias espontáneas. 
es perfectamente posible para el investigador vivir en la aldea indígena acompañando a la gente en su trabajo, observando todas las actividades importantes y describiendo el curso de la vida diaria.

\section{B. Selección de comunidades}

Al principio no se dio mucha importancia a cómo se habían de seleccionar las aldeas que iban a ser objeto de estudio. Muchos antropólogos han escrito sus monografías con datos de informantes escogidos por sus méritos sociales o de otra índole sin tener en cuenta cuál era su comunidad de origen ${ }^{44}$.

Pero en un estudio sociológico moderno, la selección de la comunidad a estudiar es muy importante, pues de ella depende el valor de las generalizaciones del etnógrafo sobre la vida de la tribu. Esto es muy importante cuando se estudia una unidad política grande como son, por ejemplo, las tribus de África Occidental; para poder juzgar qué tan representativa es una aldea determinada hay que hacer primero un reconocimiento de la región y entonces puede resultar que es necesario estudiar varias comunidades de tipos diferentes. Esto es lo que se ha hecho al estudiar tanto aldeas de nobles como de plebeyos, o como un artificio para estudiar culturas con varios grados de influencia europea ( $c f$. sección II, f).

El método de selección, que es parte de la técnica del etnógrafo, requiere más atención de la que ha recibido y se debe usar muy cuidadosamente. El etnólogo tiene problemas más complicados que los del sociólogo o el psicólogo que estudian una comunidad moderna, puesto que basándose en un pequeño grupo local trata de describir la cultura de una tribu cuyas costumbres son completamente distintas a las suyas.

\section{Duración de la investigación}

La cuestión del tiempo que se debe pasar en la comunidad indígena depende evidentemente de varios factores como: 1) el propósito del estudio, sea una inspección preliminar o una investigación intensiva; 2) la cantidad de información ya existente sobre esa comunidad y la experiencia del etnógrafo con comunidades semejantes; 3) el tamaño y la uniformidad del grupo estudiado, y la velocidad con que está cambiando su cultura.

44 Roscoe (1911, X), por ejemplo, dice que él ha obtenido información acerca de los bagandas sentado en una choza, adonde eran llevados ancianos provenientes de varias aldeas, y muchas investigaciones etnográficas se han basado casi en su totalidad en la información dada por los nativos entrevistados individualmente y no como representantes de un grupo. 
Cuando juntaba los datos para su reconocimiento de las sociedades melanésicas, Rivers pasó un mes en Hawái y otro en Fiyi, pero en algunas otras islas solo alcanzó a estar un día (Rivers 1911). Casi todos los estudios sobre tribus americanas se realizaron en visitas que duraron de uno a seis meses, probablemente debido a lo cercano del campo y a la naturaleza de la investigación. Pero en un estudio sociológico hace falta más tiempo. Hay que aprender el idioma, recoger una gran cantidad de material sobre casos concretos y observar todas las actividades de la cultura que se desarrollan solamente en ciertas estaciones del año.

Malinowski pasó dos años en las islas Trobriand en el curso de tres expediciones y aquellos de sus discípulos que han sido investigadores del Instituto Internacional de Lenguas y Culturas Africanas han trabajado en el campo dos años separados con un intervalo entre ellos. Es probable que si se quisiera hacer además un estudio muy detallado de algún aspecto de la cultura, hubiera que prolongar la duración de la expedición ${ }^{45}$. Todavía no sabemos hasta qué punto el trabajo en cooperación puede acortar el tiempo necesario, puesto que se han hecho muy pocos experimentos de este tipo.

\section{Entrevista de informantes}

Una vez seleccionada la comunidad, el antropólogo pasa a obtener su información usando varios métodos. En los primeros tiempos de la etnografía, la regla era preguntar a los indígenas todo lo que se quería averiguar. Hoy en día, la entrevista no es más que uno de los métodos de investigación, aunque uno de los más importantes. Como el capítulo XIII está dedicado a este tema no haremos más que unos pocos comentarios.

El antropólogo puede escoger a sus informantes basándose en su memoria, inteligencia, capacidad de expresión, grado de educación, o conocimientos especiales debido a su edad, rango o profesión; también es importante si sabe hablar el idioma del antropólogo y la actitud más o menos amistosa que tome hacia este ${ }^{46}$. Muy a menudo, algunos antropólogos se han confiado a uno o dos informantes que les han sido de gran valor; este procedimiento es casi inevitable

45 Read ha vuelto recientemente a Nyasalandia en su tercera visita para realizar una investigación especializada acerca de los efectos del trabajo migratorio (absentee labour) en las condiciones de vida de los nativos y en la producción de alimentos. Los dos años anteriores de trabajo de campo estuvieron dedicados al estudio general de la tribu ngoni. 
cuando se trata de reconstruir una cultura que ya ha desaparecido. De esta manera, algunos antropólogos norteamericanos nos describen cómo trabajaron con algunos informantes durante seis u ocho horas diarias a sueldo fijo y publican los nombres de sus informantes para que puedan ser consultados por otros antropólogos. En estos casos, el informante se dedica exclusivamente a dar sus datos y casi se convierte él mismo en un antropólogo. Sin embargo, todos los etnógrafos prefieren seleccionar unos pocos hombres y mujeres de cada comunidad idóneos e inteligentes.

El grado en que uno se puede fiar de la entrevista como fuente de información depende de varios factores, por ejemplo, el objeto de estudio. Si la investigación trata de hacer una reconstrucción histórica, casi todos los datos se obtendrán mediante entrevistas, mientras que en los casos de investigaciones sociológicas se tiende a limitar cada vez más las preguntas formales o a usarlas de otra manera.

Además, la cantidad de historia social estereotipada por la tradición difiere mucho en las distintas comunidades. Por ejemplo, los polinesios recitarán larguísimas genealogías de una manera desconocida entre la mayoría de los pueblos de África. Radin comenta la "memoria prodigiosa" de un indio winnebago que le estuvo contando una ceremonia compleja durante dos meses enteros trabajando a razón de seis horas diarias.

Claro es que hay varios puntos que un indígena no puede contestar cuando se le pregunta sobre ellos. Sus hábitos intelectuales difieren de los nuestros. A nosotros nos parece que le faltan conceptos de precisión matemática, mientras que a él le extraña nuestra falta de capacidad para medir distancias sin tener una cinta métrica en la mano.

Las esferas de la conducta sobre las que la gente acostumbra generalizar varían también de cultura a cultura. Así, por ejemplo, un europeo dirá enseguida cuántas horas trabaja y cuánto dinero gana; pero el indígena no sabrá el contenido exacto de su granero o el tiempo que le llevó cultivar su huerta. Por otra parte, un inglés no sabrá decir cuál debe ser su comportamiento para con su tía paterna, mientras que un melanesio o un africano lo dirá enseguida. Siempre que el antropólogo no puede obtener en entrevistas informes sobre la realidad objetiva, tiene que recurrir a la observación directa.

El uso de entrevistas se está ampliando en las investigaciones sociológicas directas, pues sirve para obtener otro tipo de datos. Por ejemplo, es de gran importancia para determinar las actitudes emotivas y los puntos de vista de los diferentes sectores de una comunidad en los casos en que se está realizando un violento cambio cultural. De hecho, muchos antropólogos han creído necesario 
citar íntegras las respuestas de sus informantes a las preguntas hechas para aclarar sus puntos de vista. Sin embargo, hemos de insistir en que el antropólogo, al contrario del psicólogo o del trabajador social, no tiene que descubrir peculiaridades psicológicas individuales, sino solamente aquellas actitudes que están definidas por la tradición para toda la sociedad o para ciertos sectores de ella. Tampoco está en situación de distinguir diferentes tipos de actitudes o de individuos hasta que haya vivido cierto tiempo en la comunidad indígena.

\section{E. El habla en acción ${ }^{47}$}

Además de preguntar a sus informantes, el antropólogo debe escuchar las conversaciones de los indígenas durante sus actividades cotidianas. De esta manera, podrá registrar formas tradicionales como rezos y conjuras que solo se pueden oír en el curso de la ceremonia en que se usan; obtendrá datos que no se consiguen con preguntas directas pero que se manifiestan durante una fiesta o ceremonia, o que puede oír en conversaciones casuales entre indígenas, y descubrirá las normas de conducta verbal características de las distintas formas de relación social. Se puede averiguar cuáles son los intereses dominantes de la gente oyendo lo que dicen y notando sus reacciones espontáneas, que no siempre se conforman a las reglas ortodoxas de la tribu. El etnógrafo de campo ha hecho más uso de esta técnica de escuchar conversaciones que el psicólogo o sociólogo que estudian una sociedad moderna ${ }^{48}$. Algunos psicólogos han observado el habla de los niños pero con los adultos no se ha hecho nada sistemático.

Registrar el habla en acción es cosa difícil. En el caso de rezos y conjuros, el antropólogo puede recoger las formas con bastante facilidad, pero cuando está escuchando una conversación, por fuerza tiene que escoger unas cosas y desechar otras. Se ha dicho que el remedio ideal sería un registro fonográfico continuo pero es dudoso el valor sociológico que pueda tener tal registro. Para decidir cuáles expresiones son típicas y cuáles no, el antropólogo debe basarse en su propio juicio madurado a través de varios meses de escuchar conversaciones semejantes. Para presentar a los lectores el resultado de estas selecciones se han intentado varios métodos. Malinowski (1935) ha analizado muchas expresiones en su contexto natural, principalmente, las de carácter mágico y las usadas para

47 Cf. Malinowski (1935) para el desarrollo de este concepto.

48 El movimiento de la "observación masiva" (mass-observation) intentó estos métodos. Véase May the Twelfth: Mass-Observation Day Surveys, de Humphrey Jennings y Charles Madge (1937, 431). 
coordinar actividades técnicas. Firth (1936) da ejemplos de conversaciones sostenidas en casa, en la playa o durante una danza.

Hunter (1936), cuando cuenta cómo se reúnen los pondos a tomar cerveza, da el número de indígenas que estuvieron en una reunión dada y ejemplos de los chistes que se decían. En estos casos, más que en otros, es necesario que el antropólogo declare cuáles son sus intereses y qué tan buena es su memoria. Es valiosa la sugerencia de Lindgren (1935) en el sentido de que se sometieran a pruebas para medir la memoria.

\section{F. Cuestionarios}

Han sido la base de muchas investigaciones sociológicas en comunidades civilizadas. Aunque evidentemente son de uso más limitado en el caso de pueblos primitivos, se han aplicado para obtener datos y a veces también para reflejar actitudes y puntos de vista. Los cuestionarios se pueden dividir en dos clases.

\section{Cuestionarios dirigidos a europeos residentes entre pueblos primitivos}

Son ejemplos el de Morgan (1860) sobre términos de parentesco dirigido por el secretario de Estado a 139 representantes diplomáticos; el de Thurnwald (1935) sobre condiciones económicas generales dirigido a los oficiales del Gobierno en África Oriental, y el preparado por el Instituto Colonial Belga para administradores del Congo, a base del cual se están preparando monografías sobre los bantúes centrales (Verhulpen 1936). Hobson Dewey Anderson y Walter Crosby Eells (1935) hicieron un experimento tratando de obtener datos sobre el temperamento de un pueblo primitivo, pidiendo a 34 residentes en Alaska - esquimales blancos casados con esquimales, misioneros, maestros y científicos - sus opiniones sobre las cualidades de los indígenas en cuanto a hospitalidad, modestia, sociabilidad y buen humor. Casi toda la información etnográfica necesitada por los gobiernos coloniales ha sido adquirida de residentes europeos por medio de cuestionarios o métodos semejantes, pero desde el punto de vista antropológico este procedimiento ha sido un fracaso. Se ha podido ver que es posible para algunos extranjeros vivir entre los indígenas toda una vida sin tener contacto con ellos y sin aprender nada de sus costumbres. Claro que hay excepciones y algunos misioneros y administradores han hecho contribuciones muy importantes a la etnografía ( $c f$. las secciones I y II. A.E.). 


\section{Cuestionarios dirigidos a indígenas ilustrados}

Se han usado mucho en América para estudios de distribución. Los africanistas también han usado a indígenas educados para registrar casos concretos y para contestar cuestionarios. Schapera los ha usado en un pueblo tswana para escribir relatos de la vida diaria y para anotar sucesos importantes ocurridos durante su ausencia, así como para llevar las cuentas de la expedición. Lo mismo ha hecho Ellen Hellmann en Johannesburgo ${ }^{49}$, Arthur Theodor y Geraldine Mary Culwick en Tanganica, Edmund Hugh Ashton entre los basutos y Hilda Beemer entre los swazis han obtenido de sus informantes diarios sobre alimentación, y el Gobierno de Nigeria ha usado el mismo método. También se han dirigido cuestionarios a maestros y empleados indígenas; la comisión Merle Davis ha usado uno en Sudáfrica y Rodesia del Norte (Davis 1933). Hasta ahora, los cuestionarios han dado sus mejores resultados en el registro de hechos concretos más que en definir opiniones y actitudes. Hay que tener en cuenta que muchos indígenas, aun cuando sepan escribir, no tienen la costumbre de contestar preguntas como un europeo que se ha acostumbrado a ello desde la escuela.

\section{G. Biografías y autobiografías}

En 1920 Radin publicó la autobiografía de un indio winnebago escrita en sus mismas palabras y después han salido varias publicaciones semejantes (Michelson 1933; Steward 1934). No hay duda de que de esta manera se pueden obtener muchos datos sobre una cultura, aunque si fuera la única fuente tendría menos valor que las observaciones del antropólogo sobre esa misma tribu ${ }^{50}$. Las biografías se han usado con dos fines principales: revelar la vida típica de un indígena tomando a un individuo como ejemplo e ilustrar reacciones individuales hacia ciertas instituciones de la tribu, tales como el ayuno y los sueños sobre espíritus protectores de muchas tribus norteamericanas. El éxito que se obtenga de este segundo punto depende de lo común que sea en la tribu la introspección, no es de extrañar por lo tanto que se iniciara este método para estudiar tribus de Norteamérica con una religión muy individualista. Sería muy importante comparar los informes orales con los escritos por los indígenas que han aprendido

\footnotetext{
49 Véase Hellmann (1935, 1936, IX, 277-290).

50 E. Demant Hatt persuadió a un lapp kantokeiko para que preparara (en 1907-1908) un escrito en finlandés y en lappish, y luego él publicó la traducción al danés en 1911; esto pertenece a una categoría diferente. Este documento muy apreciado con las notas de la señora Hatt trata de muchos aspectos descritos por autores escandinavos y otros más durante varias centurias (Hatt 1931) .- E. J. L. (SIC)
} 
hace poco a escribir y que viven en comunidades donde la mayoría de la gente es analfabeta.

\section{H. Documentación concreta}

Por lo general, las monografías de los primeros antropólogos presentan todos sus datos en forma de afirmaciones categóricas, por ejemplo, que en la tribu fulana son industriosos cazadores de cabezas, matrilineales, comunistas o lo que sea. Más tarde, ya se empezó a dar forma más concreta al material en que se basan las generalizaciones, describiendo incidentes de la vida diaria, citando textos indígenas, nombrando a los informantes, publicando cierto número de sucesos concretos, etc. Se empezó a reconocer la diferencia que hay entre las normas teóricas de la tribu y la realidad de los hechos que muestran esa divergencia. Los etnógrafos han comenzado a acumular material sobre casos concretos de manera semejante a como lo hacen los sociólogos, cuyos métodos han influido en las nuevas técnicas de la etnografía.

Los datos recogidos se refieren a la composición de los grupos sociales, clanes, aldeas y generaciones, y a la frecuencia de costumbres especiales como ciertas formas de matrimonio, etc. Los casos concretos no se usan para averiguar características individuales sino para determinar cuál es la vida típica de los miembros de la tribu y cuáles sus creaciones a las normas establecidas. El material de este tipo ha sido sumamente valioso para aumentar el campo de la información del antropólogo y para permitirle generalizar sobre instituciones y comportamientos en casos en que el indígena es incapaz de hacerlo ${ }^{51}$. Finalmente, se han hecho algunos esfuerzos por estimar la frecuencia de usos particulares y formas de comportamiento.

El desarrollo de la investigación concreta ha sido gradual. En 1912, Rivers recomendó la recolección de genealogías como un modo de reconstruir la historia de los términos de parentesco en Melanesia y actualmente ese es el método usado para el estudio del parentesco de cualquiera que sea la orientación teórica. En 1922, Malinowski insistía en la importancia de publicar planos de las aldeas y de la propiedad agrícola, análisis cuantitativos de la distribución de la riqueza, de la composición de los clanes y relatos de incidentes de la vida diaria. Su libro Coral Gardens and their Magic (1935) es probablemente la obra etnográfica más documentada sobre esos aspectos de todas las aparecidas hasta

51 Así, un informante inteligente puede describir solo el tipo más común de los contratos matrimoniales, mientras que un censo casa por casa puede revelar cinco o seis formas anómalas. 
la fecha. Actualmente se publican en las monografías censos sociológicos, especialmente de aldeas, que muestran los agrupamientos de clases, tipos de matrimonio, estructura de parentesco y movimientos de población; además se da su localización en el espacio y también se transcriben casos judiciales, tanto de los tribunales indígenas como de los europeos (Benedict 1935a; Culwick y Culwick 1935b; Evans-Pritchard 1937; Firth 1936; Fortune 1932; Hunter 1936; Mead 1919; Richards 1935b).

Mead (1919), preparada al principio en psicología infantil, ha adaptado el método de casos individuales a su estudio de grupos de muchachas adolescentes en Samoa y ha analizado estadísticamente algunos de sus resultados. El uso de autobiografía se ha analizado en la sección III, G y los etnógrafos americanos son los que han publicado más textos indígenas.

Los intentos de estimar los ingresos de los indígenas o su nivel de vida han encontrado grandes dificultades. Schapera ha hecho sus cálculos en un pueblo tswana mediante presupuestos anuales y cómputos del número de cabezas de ganado y del contenido de los graneros, usando también datos de los libros de comerciantes. El Gobierno de Nigeria ha usado procedimientos semejantes para imponer los impuestos. Daryll Forde (1937) ha calculado los ingresos en especie de un pueblo del sur de Nigeria. Para estadísticas de ingresos o producción véanse también las obras de Culwick y Culwick (1935b), Brown y Hutt (1935), Hunter (1936), Fortes y Richards.

La cuestión de la expresión estadística de los datos antropológicos es también difícil. El investigador trata con gente analfabeta, no tiene estadísticas oficiales fidedignas, maneja una gran cantidad de material que no se puede expresar estadísticamente y, sobre todo, no querrá sacrificar el estudio detallado de una comunidad para poder recoger la gran cantidad de datos necesaria para obtener un muestreo satisfactorio de la tribu entera. Algunos fenómenos como el matrimonio han sido tratados estadísticamente, pero hay que cuidarse de que el deseo de obtener datos objetivos mediante métodos estadísticos no nos lleve a resultados erróneos.

\section{Observación directa de la conducta}

Hasta ahora el material etnológico ha consistido en gran parte en descripciones del medio ambiente de la cultura material y esto es inevitable en el caso de comunidades completamente distintas a las nuestras. El sociólogo que escribe sobre una comunidad moderna no tiene que explicar qué quieren decir palabras como camión, cartero o tribunal; por eso, en el caso del antropólogo, 
tienen más importancia la técnica descriptiva y el uso de los informes obtenidos por observación directa. Claro que su presentación es selectiva en alto grado. El investigador se interesa por costumbres que son muy distintas a las suyas 0 semejantes a las de otras comunidades que ha estudiado, por hechos que según su experiencia previa sabe que son significativos. Y por aquellas maneras de comportarse que se relacionan con sus intereses teóricos. Algunas veces pone atención durante mucho tiempo en determinado tema antes de llegar a una conclusión ${ }^{52}$, pero en cualquier caso la selección es muy arbitraria.

Los relatos de actividades organizadas como son las de carácter ceremonial o económico han ocupado un lugar importante en las monografías etnográficas, aunque no siempre se puede decir, leyendo los datos, si el etnógrafo presenció el suceso o lo reconstruyó con ayuda de informantes. Sin embargo, la manera de presentar el material ha mejorado mucho en cuestiones de detalle añadiendo a las anteriores descripciones de qué pasaba, datos sobre quiénes actuaban y cómo se comportaban ${ }^{53}$. Se ha intentado anotar la sucesión de actividades y la manera como los indígenas pasan el tiempo para elaborar ciclos anuales, mensuales y aun diarios, no solo para todo el grupo sino también para los individuos ${ }^{54}$. La observación de actividades no organizadas como la etiqueta y la educación de los niños fue descuidada al principio debido principalmente a que no tienen valor dramático, pero actualmente los antropólogos tratan de registrar todos esos aspectos de la vida. Aquí la dificultad está otra vez en la selección. Al antropólogo le interesan solo aquellas normas de comportamiento definidas por la tradición y, en algunos casos, esas normas son difíciles de reconocer ${ }^{55}$. La solución estriba

52 El observador que va al campo preparado para estudiar los métodos educativos de la gente, observará cuidadosamente las veces que él vio cuando se castigaba a un niño, pero podría ocurrir que al final de su investigación accidentalmente mirara cuando un niño fuera abofeteado y percatarse de pronto de que él no ha sido testigo anteriormente de algo semejante. Cfr. la "percepción de un adiestrado trabajador social" en el capítulo XV, sección VII, C, 2.

53 La posibilidad de una descripción compleja varía de acuerdo con el conocimiento de la cultura por parte del etnógrafo y del número de generalizaciones acertadas que él ya haya formulado acerca del sistema de relaciones. El recién llegado puede registrar con suficiente precisión, "la gente fue a la pesca del bonito", información que podría proporcionar un documental. El etnógrafo que comprende la organización social de la tribu y está familiarizado con las relaciones entre los habitantes de la aldea podría en cambio sustituir ese registro por el siguiente: "X fue a la pesca del bonito con Y, porque Y es su tío materno y tiene la obligación legal de acompañarlo. Él escupió al aire, no para aclarar su garganta, sino para invocar la bendición de los espíritus".

Véase Richards (1935b).

Cfr. la afirmación de Mead de que los métodos de dar de mamar a los infantes son tan estandarizados como los métodos de deshacerse ritualmente del cordón umbilical, pero estos últimos pueden conocerse mediante preguntas y respuestas, mientras que los primeros solo se conocerán luego de un largo proceso de observación (Mead 1933, I). 
en que el antropólogo esté constantemente formulándose nuevos problemas de acuerdo con sus intereses, y no acumulando datos y más datos sobre sucesos cotidianos. Por esto es digna de tener en cuenta la sugerencia hecha a los etnógrafos de que por cada tres semanas que pasan en el campo, estén una examinando y analizando el material ya obtenido.

\section{Presentación del material}

En la presentación de su material, el antropólogo encuentra dificultades especiales. Debe explicar las instituciones sociales de una gente cuyo ambiente, cultura material y normas de conducta son totalmente desconocidos para la mayoría de sus lectores. Si trata de hacer "ver" a sus lectores un rincón de la aldea, una danza ceremonial o el curso de la vida diaria dentro de una choza, le comunicará impresiones que sin duda son muy subjetivas. No hay palabras exactas para describir la conducta humana, el porte y la expresión de la gente, de modo que hay cierta tendencia a considerar no científicas las descripciones sobre esos temas.

Cuando un autor no logra distinguir claramente sus propias emociones y opiniones, las que atribuye a los miembros de la tribu, puede comunicar falsas impresiones a sus lectores. Pero omitir esos relatos vividos de cosas presenciadas por él puede traer consigo la pérdida de algo que puede ser esencial para la comprensión de la vida social de la tribu. Los autores que dan análisis abstractos de los términos de parentesco sin describir cómo se comporta la gente no obtienen por ello objetividad científica, puesto que lo que presentan no es sino sus propias generalizaciones abstractas, basadas en lo que han observado. En vez de omitir el material descriptivo, sería mejor intentar un examen más rígido de las inclinaciones del observador y de una definición más precisa de los términos usados para describir la conducta humana ${ }^{56}$. En otros casos, el dilema del antropólogo consiste en que trata de coordinar los informes etnográficos generales como los necesarios para propósitos comparativos o estudios de distribución con una descripción sociológica y psicológica detallada de la conducta humana.

56 Esto obviamente resulta muy importante para aquellos investigadores de campo que basan sus generalizaciones acerca del patrón cultural o ethos de un grupo a partir de impresiones subjetivas, como es el caso de las descripciones de Benedict (1935b), Mead (1935) y Bateson (1936) acerca de la conducta de diferentes tribus como "dionisíacas", "dóciles", "fanfarrones", "alegres", "cooperativos" y otros más. 
La presentación de los comentarios y opiniones de los indígenas implica también un compromiso. A algunos puede parecer arbitrario escoger el dicho de un informante y descartar el de otros, pero es imposible publicar todo el material escogido y por lo común no se puede llegar a estimaciones cuantitativas con material de ese tipo. También, en este caso, el deseo de lograr objetividad ha resultado en no publicar muchos datos interesantes ni tampoco las propias opiniones del etnógrafo. En algunas de las contribuciones más importantes de la antropología americana se han publicado textos enteros, casi siempre con el nombre de los informantes, pero muchas veces sin comentarios ${ }^{57}$. De igual modo, las autobiografías de indígenas se han publicado sin explicaciones.

Con tal procedimiento se gana cierto grado de objetividad y el valor lingüístico de los textos es evidente. Pero desde el punto de vista sociológico, es esencial que el investigador diga lo que sabe sobre la edad, rango, grupo social, educación y grado de contacto con otras culturas del informante, a condición de que seleccione los datos que da sistemáticamente y explique sus razones para hacerlo. Al estudiar sociedades en las que el grado de variación es grande debido a la estratificación social o a contactos con culturas invasoras, se tiende actualmente a dar ejemplos de las opiniones de los indígenas que contribuyen más a una comprensión correcta de la sociedad de lo que puede hacer una biografía o un texto sin comentarios. Siempre que se pueda se deben incluir materiales de los dos tipos.

En la presentación de los datos contenidos en biografías o en relatos de sucesos determinados surgen problemas semejantes. El material sobre formas de matrimonio o la frecuencia del divorcio se puede manejar estadísticamente, no así las biografías o incidentes notables de la vida de la tribu. No parece posible publicar listas enteras de sucesos que ilustran algún aspecto de la cultura y además sería difícil para un lector no familiarizado con esa cultura sacar generalizaciones propias de ellos. Pero tampoco es satisfactorio presentar generalizaciones sin el material en que se basan. Un compromiso adoptado por muchos etnógrafos consiste en dar relatos generalizados de la organización de la tribu, ilustrados con una selección de casos concretos. También se pueden añadir variaciones individuales de interés especial. Algunos antropólogos ${ }^{58}$ han descrito detalladamente el carácter, la apariencia y el comportamiento de sus principales

Boas estableció con vigor la importancia de publicar textos nativos sin comentarios. Gifford (1922) enumera los nombres de 150 informantes que le proporcionaron información para su investigación sobre el parentesco en California, sin proporcionar ningún análisis descriptivo. Cf. también Radin (1933) por sus comentarios críticos a este procedimiento. 
informantes, de modo que el lector se da cuenta de los acontecimientos en que participaron y de las maneras en que suministraron sus informes.

\section{Conclusión}

La antropología social está en proceso de convertirse en una ciencia de observación. Sus intereses teóricos han pasado de los primeros esquemas comparativos y evolucionistas y descripciones superficiales, por un lado, a reconstrucciones históricas detalladas a base de estudios de cambio cultural y de distribución, y por otro, a análisis sociológicos detallados de culturas determinadas. Las técnicas del etnógrafo de campo no han alcanzado la precisión de las de otras ciencias sociales y tal vez nunca la alcancen debido a lo enorme de su objeto de estudio, la falta de información previa sobre la región y cultura que estudia y el analfabetismo de la gente con que trata. Sin embargo, el antropólogo de campo ha ejercido una influencia considerable sobre los investigadores de sociedades modernas debido principalmente a la amplia visión de la cultura que ha logrado alcanzar, a que trata con sociedades enteras y no con subdivisiones de ellas ${ }^{59}$, a que no está identificado con los valores del grupo que estudia y a que observa directamente las normas de conducta y las reacciones emotivas de todos los sectores de la sociedad.

Traducción: Pedro Carrasco, ENAH, 1944

Recuperación de notas y referencias: Roberto Melville, 2012 http://www.ciesas.edu.mx/clasicos/publicaciones/index.html

\section{Referencias}

Anderson, H. Dewey y Walter Crosby Eells. 1935. Alaska Natives: A Survey of their Sociological and Educational Status. Palo Alto, CA: Stanford University Press.

Bartlett, sir Frederic Charles. 1923. Psychology and Primitive Culture. Nueva York: Macmillan.

59 La mayoría de las encuestas de comunidades modernas quedan restringidas a las clases que se encuentran debajo de la línea de la pobreza (CFR. capítulo XVIII). 
—. 1937. "Psychological Methods and Anthropological Problems”. Africa 10 (4): 401-420.

Bateson, Gregory. 1934. "Field Work in Social Psychology in New Guinea”. En Congress International des Sciences Anthropologiques et Ethnologiques. Compterendu de la premiere session. Institute Royal d' Anthropologie, Londres, 31 de julio.

—. 1935. "Culture Contact and Schismogenesis". Man XXXV: 178-183.

—. 1936. Navem. Cambridge, UK: Cambridge University Press.

Benedict, Ruth. 1930. "Psychological Types in the Cultures of the Southwest". XXIII International Congress of Americanists, Nueva York.

—.1935a. Zuni Mythology. Nueva York: Columbia University Press.

-. 1935b. Patterns of Culture. Londres: Routledge.

Blackwood, Beatrice. 1927. A Study of Mental Testing in Relation to Anthropology. Mental Measurements Monographs, Serial 4. Baltimore, Md.: The Williams \& Wilkins Co.

Boas, Franz. 1900. Introducción a The Jesup North Pacific Expedition, I. Memoirs of the American Museum of Natural History, II, 3-6.

—. 1920. “The Methods of Ethnology”. American Journal of Archaeology XXII: 311-321.

—. 1930. "Anthropology". En Encyclopedia of the Social Sciences, editado por Edwin R. A. Seligman, vol. II, 73-110. Londres: Macmillan.

Brown, George Gordon y Alexander McDonald Bruce Hutt. 1935. Anthropology in Action. Londres: Oxford University Press.

Chinnery, Ernest William Pearson y Alfred Cort Haddon. 1917. "Five New Religious Cults in British New Guinea”. Hibbert Journal XV: 448-463.

Culwick, Arthur Theodore y Geraldine Mary Culwick. 1935a. "Culture Contact on the Fringe of Civilization”. Africa 8 (2): 163-170.

-. 1935b. Ubena of the Rivers. Londres: Allen and Unwin.

Davis, John Merle. 1933. Modern Industry and the African. An Enquiry into the Effect of the Copper Mines of Central Africa upon Native Society and the Work of Christian Missions. Londres: Macmillan.

Deacon, Arthur Bernard. 1934. Malekula. Londres: Routledge.

Eggan, Fred, ed. 1937. Social Anthropology of North American Tribes. Chicago, Ill.: University of Chicago Press.

Elkin, Adolphus Peter. 1932. "Social Organization in the Kimberley Division”. Oceania II (3): 296-333.

—. 1933. "Studies in Australian Totemism”. Oceania Monographs. Sídney: Sydney Australian National Research Council.

Evans-Pritchard, Edward Evan. 1937. Witchcraft, Oracles and Magic among the Azande. Oxford: Clarendon Press. 
Firth, Raymond. 1936. We, the Tikopia. Londres: Allen and Unwin.

Fison, Lorimel y Alfred William Howitt. 1880. Kamilaroi and Kurmai. Melbourne: Robertson.

Forde, Cyril Daryll. 1937. “Land and Labour in a Cross River Village, Southern Nigeria”. The Geographical Journal 90 (1): 24-51.

Fortes, Meyer. 1936. “Culture Contact as a Dynamic Process”. Africa 9 (1): 24-55.

Fortune, Reo. 1932. Sorcerers of Dobu. Londres: Routledge.

Frazer, James George. 1916. Questions on the Customs, Beliefs, and Languages of Savages. 3. ${ }^{\text {a }}$ imp. Cambridge, UK: Cambridge University Press.

Frobenius, Leo y Ritter von Wilm, ed. 1921-1922. Atlas Africanus: Belege zur Morphofogie der Afrikanischm Kulturen. Múnich: Beck.

Gifford, Edward Winslow. 1922. “Californian Kinship Terminologies”. Berkeley: University of California Press.

Haddon, Alfred Cort. 1895. Evolution in Art. Londres: Scott.

Haddon, Alfred Cort, William Halse Rivers, Charles Gabriel Seligman, Charles Samuel Myers, William McDougall, Sidney Herbert Ray, Anthony Wilkin. 1901-1935. Report of the Cambridge Anthropological Expedition to Torres Strait. 6 vols. Cambridge, UK: Cambridge University Press.

Hailey, Lord. 1938. An African Survey. Londres: Oxford University Press.

Hatt, Emilie Demant. 1931. Turi's Book of Lappland. Londres: Jonathan Cape.

Hellmann, Ellen. 1935. "Native Life in a Johannesburg Slum Yard”. Africa 8 (1): 34-62.

—. 1936. "Urban Native Food in Johannesburg”. Africa 9 (2): 277-290.

Herskovits, Melville Jean. 1937. Life in a Haitian Valley. Nueva York: Knopf.

- .1938a. Acculturation. The Study of Culture Contact. Nueva York: Augustin.

-.1938b. Dahomey, an Ancient West African Kingdom. Nueva York: Augustin.

Herzog, George. 1935. "Special Song Types in North American Indian Music”. Zeitschrift fur Vergleichende Musikwissenschaft 3 (1): 23-33.

Hocart, Arthur M. 1929. "Lau Islands, Fiji”. Bernice Pauahi Bishop Museum Bulletin 62. Honolulu.

Hogbin, Ian L. 1934a. “Culture Change in the Solomons”. Oceania IV (3): 233-267.

-. 1934b. Law and Order in Polynesia. Londres: Christophes.

Hunter, Monica. 1934a. "Methods of Study of Culture Contact”. Africa 7 (3): 335-350.

-. 1934b. "Notes on Changes in Xosa Resulting from Contact with Europeans". Africa 7 (1): 100-104.

-.1936. Reaction to Conquest. Nueva York: Oxford University Press. 
Ivens, Walter G. 1917. Melanesians of the South-east Solomon Islands. Londres: Kegan Paul.

Keesing, Felix Maxwell. 1928. “The Changing Maori”. Memoirs, Board of Maori Ethnological Research, vol. 4. New Plymouth, Nueva Zelanda: Thomas Avery \& Sons.

—. 1934. Modern Samoa. Londres: Allen \& Unwin.

Klimek, Stanisław. 1935. "Culture Element Distributions I: The Structure of California Indian Culture”. University of California Publications in American Archaeology and Ethnology XXXVII (I): 1-70.

Klimek, Stanislaw y Edward Winslow Gifford. 1936. "Culture Element Distributions II: The Structure of California Indian Culture”. University of California Publications in American Archaeology and Ethnology XXXVII (II): 71-100.

Koppers, Wilhelmm. 1924. Unter Feuerland Indianern. Stuttgart: Strecker and Schröder.

Krige, Eileen Jensen. 1936. "Changing Conditions in Marital Relations and Duties among Urbanized Natives”. Africa 9 (1): 1-23.

Kroeber, Alfred Louis y Harold E. Driver. 1932. "Quantitative Expression Cultural Relationships”. University of California Publications in American Archaeology and Ethnology 31 (4): 221-256.

Lesser, Alexander. 1933. "The Pawnee Ghost Dance Hand Game”. Columbia University Contributions to Anthropology, vol. 16. Nueva York: Columbia University Press.

Lindgren, Ethel John. 1934. "Field Work in Social Psychology in Eastern Asia”. I Congrès International des Sciences Anthropologiques et Ethnologiques.

—. 1935. "Field Work in Social Psychology”. British Journal of Psychology 26 (2): 174-182.

-. 1938. "An Example of Culture Contact without Conflict". American Anthropologist 40 (4): 605-621.

Linton, Ralph. 1936. The Study of Man. Nueva York: Appleton Century Crofts, Inc.

Lowie, Robert. 1935. The Crow Indians. Nueva York: Farrar \& Rinehart.

Lynd, Robert Staughton y Helen Merrell Lynd. 1929. Middletown: A Study in Modern American Culture. Londres: Harcourt Brace \& World.

Mair, Lucy Philip. 1934a. An African People in the Twentieth Century. Londres: Routledge.

-. 1934b. "The Study of Culture Contact as a Practical Problem”. Africa 7 (4): 415-422.

Malinowski, Bronisław. 1922. Argonauts of the Western Pacific. Londres: Routledge.

—. 1929a. "Practical Anthropology”. Africa 2: 22-38.

—. 1929b. The Sexual Life of Savages. Londres: Routledge.

-. 1931. "Culture”. En Encyclopedia of the Social Sciences, editado por Edwin R. A. Seligman, IV, 621-646. Londres: Macmillan.

-. 1935. Coral Gardens and their Magic. 2 vols. Londres: Allen \& Unwin.

-. 1938. "Introductory Essay: The Anthropology of Changing African Cultures”. En Methods 
of Study of Culture Contact in Africa, International Institute of African Languages and Cultures, VII-XXXVIII. Memorandum XV. Londres; Nueva York: Oxford University Press.

Mead, Margaret. 1919. Coming of Age in Samoa. Londres: Jonathan Cape.

-. 1930. The Changing Culture of an Indian Tribe. Columbia University Contributions to Anthropology, vol. XV. Nueva York: Columbia University Press.

-. 1932. “An Investigation of the Thought of Primitive Children”. Royal Anthropological Institute of Great Britain and Ireland 62: 173-190.

—. 1933. "More Comprehensive Field Methods". American Anthropologist 35: 1- 15.

-. 1935. Sex and Temperament in Three Primitive Societies. Londres: Routledge.

Meek, Charles Kingsley. 1931. A Sudanese Kingdom. Londres: Kegan Paul.

Michelson, Truman. 1933. “Narrative of an Arapaho Woman”. American Anthropologist 35 (4): 595-610.

Mill, James Philip. 1926. The Ao Nagas. Londres: Macmillan.

Myres, John Linton. 1929. “The Science of Man in the Service of the State”. Journal of the Royal Anthropological Institute LIX: 9-52.

Nadel, Siegfried Frederick. 1929. Notes and Queries in Anthropology, 5. ${ }^{\mathrm{a}}$ ed. Londres: The Royal Anthropological Institute.

—. 1937. “The Typological Approach to Culture”. Character and Personality 5 (4): 267-284.

Oliver, Richard A. C. 1933. "The Adaptation of Intelligence Tests to Tropical Africans". Overseas Education 4: 40-46.

Pitt-Rivers, George Henry Lane Fox. 1911. The Clash of Culture and the Contact of Races. Londres: Routledge.

Porteous, Stanley D. 1931. The Psychology of a Primitive People. Londres: Arnold.

Radcliffe-Brown, Alfred Reginald. 1924. "The Mother's Brother in South Africa”. South African Journal of Science 21: 542-515.

—. 1930. “The Social Organization of Australian Tribes”. Oceania 1 (3): 322-341.

-. 1931. "The Present Position of Anthropological Studies". Report of the British Association for the Advancement of Science, Centenary Meeting, Londres, Presidential Address (Section H): 141-171.

Radin, Paul. 1913. "The Influence of Whites in the Winnebago Cultures”. Proc. State Historical Society of Wisconsin, 137-145. Madison: Pub. for the Society.

-. 1920. "The Autobiography of Winnebago Indian”. Publications in American Archaeology and Ethnology 16 (7): 381- 473.

-. 1933. The Method and Theory of Ethnology. Londres: McGraw Hill. 
Rasmussen, Knud. 1931. “The Netsilik Eskimos”. Report of the Fifth Thule Expedition, 1921-4. Copenhague: Gyldendal.

Read, Margaret. 1938. "Native Standards of Living and African Culture Change”. International Institute of African Languages and Cultures, Memorandum XVI. Londres: Oxford University Press.

Redfield, Robert. 1930. Tepoztlan, a Mexican Village. Chicago: Chicago University Press.

Richards, Audrey. 1932. "Anthropological Problems in North-Eastern Rhodesia”. Africa 5 (1): 121-144.

—. 1935a. "The Village Census in the Study of Culture Contact”. Africa 8 (1): 20-33.

-. 1935b. Land, Labour and Food in Northern Rodhesia. Londres: Oxford University Press.

Rivers, William Halse. 1900. "A Genealogical Method of Collecting Social and Vital Statistics”. The Journal of the Anthropological Institute of Great Britain and Ireland XXX: 74-82.

—. 1911. The History of Melanesian Society. Cambridge, UK: Cambridge University Press.

Roheim, Géza. 1915. Australian Totemism: A Psycho-Analytic Study in Anthropology. Londres: Allen \& Unwin.

Roscoe, John. 1911. The Baganda. Londres: Macmillan.

—. 1913. The Bakitaraa. Cambridge, UK: Cambridge University Press.

—. 1915. The Northern Bantu. Cambridge, UK: Cambridge University Press.

The Royal Anthropological Institute. 1874. Notes and Queries in Anthropology, 1. ${ }^{\mathrm{a}}$ ed. Londres: The Royal Anthropological Institute.

Sapir, Edward. 1916. "Time Perspective in an Original American Culture”. Memoir (Geological Survey of Canada). Anthropological Series 13. Ottawa: Government Printing Bureau.

Schapera, Isaac. 1928. "Economic Changes in South African Native Life”. Africa 1 (2): 170-188.

—. 1935. "Field Methods in the Study of Modern Culture Contacts". Africa 8 (3): 315-328.

Schebesta, Paul. 1927. Bei den Urwaldzwergen von Malaya. Leipzig: Brockhaus.

—. 1933. Bambuli: die Zwerge von Kongo. Leipzig: Brockhaus.

Seligman, Charles Gabriel. 1910. The Melanesians of British New Guinea. Cambridge, UK: Cambridge University Press.

—. 1928. “The Unconscious in Relation to Anthropology”. British Journal of Psychology XVIII: 373-387.

—. 1929. "Anthropology, Applied”. Encyclopedia Britannica, 14. ${ }^{\text {a }}$ ed., vol. II, 46-50.

Seligman, Charles Gabriel y Brenda Z. Seligman. 1932. The Pagan Tribes of the Nilotic Sudan. Londres: Routledge.

Smith, Edwin William. 1927. The Golden Stool. Londres: Edinburgh House Press. 
Spier, Leslie. 1921. "The Sun Dance of the Plains Indians”. Anthropological Papers of the American Museum of Natural History XVI: 451-527.

-. 1930. "Klamath Ethnography". University of California Publications in American Archaeology and Ethnology, vol. 30. Berkeley: University of California Press.

Steward, Julian Haynes. 1934. “Two Paiute Autobiographies”. University of California Publications in American Archaeology and Ethnology 33 (5): 423-438.

Thurnwald, Richard C. 1935. Black and White in East Africa. Londres: Routledge.

Van Gennep, Arnold. 1904. Tabou et totémisme á Madagascar: étude descriptive et théorique. Vol. XVII de Bibliothèque de l'Ecole des Hautes Études: Sciences Religieuses. París: Leroux.

Verhulpen, Edmond. 1936. Baluba et Baluhaisés du Katango. Antwerp: L’Avenir Belge.

Wagner, Günter. 1936. "The Study of Culture Contact and the Determination of Policy”. Africa 9 (3): 317-331.

Williams, Francis Edgar. 1928. Orokaiva Magic. Londres: Oxford University Press.

-. 1933. "The Vailala Madness and the Destruction of Native Ceremonies in the Gulf Division”. Territory of Papua. Anthropological Report Series 4. Port Moresby: Edward George Baker, Government Printer.

Wissler, Clark. 1922. The American Indian. Londres: Oxford University Press.

-.1923. Man and Culture. Londres: Harrap. 